\title{
GIBRALTAR Y SU CAMPO: UN ESTUDIO REGIONAL DE LAS RELACIONES INTERNACIONALES DE ESPAÑA DURANTE LA PRIMERA GUERRA MUNDIAL ${ }^{1}$
}

\author{
CAROLINA GARCÍA SANZ \\ Instituto de Historia (CSIC)
}

RESUMEN: El vacío historiográfico sobre Gibraltar durante la Primera Guerra Mundial constituye un caso específico del "problema» que reviste el análisis histórico contemporáneo sobre la colonia. Las diferentes formas de pensar "la plaza», en clave espanola, inglesa y gibraltareña, explicarían la carencia de estudios monográficos coberentes con la lógica integradora del contexto transnacional de referencia. En este artículo, a partir de la reflexión acerca de las limitaciones del tratamiento histórico de Gibraltar, derivadas de fronteras políticas y mentales arbitrarias, proponemos contribuir al estudio de la Guerra Mundial en España sacando a la colonia de la anécdota durante el período. Para ello relacionaremos las distintas actividades estratégicas dirigidas por los ingleses desde el enclave con las dinámicas económicas, sociales y políticas que al socaire de las mismas se generaron en su hinterland y que requirieron la toma de posición de los distintos gobiernos españoles entre la buena vecindad y la inteligencia bilateral con Gran Bretaña.

Palabras clave: Primera Guerra Mundial. Gibraltar. España. Campo de Gibraltar. Neutralidad.

ABSTRACT: The lack of secondary sources on Gibraltar during the First World War is due to the «problem» encountered in modern and contemporary bistorical analysis of the

1 El presente artículo supone la publicación de las primeras conclusiones de una investigación en curso enmarcada en el proyecto de tesis doctoral «Andalucía y Gibraltar durante la Primera Guerra Mundial: Economía, Política y Relaciones Internacionales» financiado con una beca FPU del Ministerio de Educación y Ciencia. Este trabajo no hubiera sido posible sin la ayuda de Fernando García Sanz, que puso a mi disposición algunos resultados del proyecto de investigación por él dirigido (2002-2005) «Espionaje y relaciones internacionales: los servicios de información aliados en España durante la Primera Guerra Mundial» (Mcyt, BHA 2002-01143), y del actualmente vigente y de cuyo equipo de investigación formo parte «Contraespionaje, seguridad y relaciones internacionales en España durante la Primera Guerra Mundial» HUM 2006-01933/HIST). 
British colony. The different ways of thinking about "Gibraltar», from the Spanish, English and Gibraltarian points of view, create a fragmented panorama of studies, barely coherent with the transnational logic of the referential context. In spite of the limitations of approaches dependent on arbitrary frames of reference and political borders, this article contributes to Spanish historical study of the Great War, setting relations between British strategic activities in Gibraltar and the economic, social and political dynamics generated in the Campo Region by taking into consideration the Spanish Government's attitudes towards good neighbourliness and Spanish-British bilateral understanding.

KEY WORDS: $\quad$ First World War. Gibraltar. Spain. Campo Region. Neutrality.

"Gibraltar was probably the most «international» of the bases and where cooperation between the Allies seemed better than at other points in the Mediterranean ${ }^{2}$

Nada más estallar la crisis bélica Gran Bretaña solicitó a España una garantía sobre el aprovisionamiento de Gibraltar. El 14 de agosto de 1914 el embajador de España en Londres trasladó al Foreign Office la voluntad de su Gobierno de facilitar el abasto de la colonia desde su territorio. Esta decisión del Gabinete de Eduardo Dato confirmó la orientación hacia la Entente que la política exterior española había adoptado con el nuevo siglo. A pesar de que en esos primeros momentos el flujo de suministros a Gibraltar no se vio alterado decisivamente por los acontecimientos internacionales, el compromiso de España en esta materia reforzó la posición de los británicos en el Estrecho, proporcionándoles un colchón de seguridad en el plano de la logística que les permitió centrar sus esfuerzos en la estrategia para el Mediterráneo occidental. Una base de operaciones como Gibraltar, situada en un punto nodal para el tráfico marítimo y mercante, significó una clara ventaja para los aliados en una guerra de desgaste que requirió para lograr la victoria el control de los recursos y sus circuitos comerciales.

En el presente trabajo pretendemos contribuir al estudio de las relaciones de España con la Entente durante la guerra tomando como referencia su política en torno a Gibraltar. Para ello, nuestra argumentación se articula sobre dos partes: una introducción de cariz historiográfico, en la que reflexionamos sobre el vacío existente en la historia de la colonia para este período, lamentablemente reducido a la anécdota por el estereotipo, y una segunda en la que, a partir de los primeros resultados de una investigación en curso, analizamos la aportación de la plaza al esfuerzo bélico de los aliados a través de las dinámicas políticas y económicas generadas en el Campo de Gibraltar.

2 Halpern, Paul G.: A Naval History of World War I, London, UCL Press, 1994, p. 395. 


\section{LA PRIMERA GUERRA MUNDIAL EN EL MARCO DEL «PROBLEMA» HiSTÓRI- CO E HISTORIOGRÁFICO EN TORNO A GIBRALTAR.}

\subsection{La historia de Gibraltar, una historia de imágenes}

La historia contemporánea de Gibraltar está imbuida de la percepción conflictiva que de la misma tienen sus habitantes — pasando por sus vecinos españoles - hasta los políticos de la metrópoli. Estos puntos de vista construyen historias diferentes $\mathrm{o}$, propiamente, versiones que en algunos episodios encuentran un campo abonado para la formación de identidades colectivas. Gibraltar, por sus connotaciones añadidas, se incluye en la categoría historiográfica de los llamados «lieux de memoires»3. Existe un Gibraltar inglés, pero también un Gibraltar gibraltareño (aunque distinto, concomitante con el inglés) y un Gibraltar español. A continuación abordaremos distintas formas de reconstruir el pasado de la colonia para comprender mejor por qué la Primera Guerra Mundial ha pasado de soslayo por las historias de Gibraltar.

\subsubsection{El Gibraltar inglés ${ }^{4}$}

La toma del Peñón fue uno de los primeros hitos de la carrera inglesa por la hegemonía marítima en el siglo XVIII, convirtiéndose en símbolo de poder emergente frente a Francia ${ }^{5}$. La resistencia a los asedios hispano-franceses durante la Guerra de la Independencia de las colonias norteamericanas dio carta de naturaleza a una vieja idea: la inexpugnabilidad de la fortaleza. "As safe as the Rock of Gibraltar» implicó algo más que una frase hecha, se identificó con la perdurabilidad del Imperio.

No es extraño, por tanto, que el enfoque militar tradicionalmente haya primado en la forma de pensar y escribir sobre «Gibraltar» ${ }^{6}$. Los asedios del siglo XVIII, sublimados en el Gran Asedio (1779-1782), junto a la Segunda Guerra Mundial son dos de los episodios que más páginas han reunido en las

3 Sobre la aplicación a Gibraltar del concepto de P. Nora «lugares de la memoria», vid. LAMBERT, David: «As solid as the Rock? Place, belonging and the local appropriation of imperial discourse in Gibraltar» en Transactions of the Institute of British Geographers, 30 Issue 2, (2005), p. 212.

4 Los siguientes inventarios bibliográficos sobre Gibraltar nos introducen en un misceláneo panorama de títulos: (1) GREEN, Muriel M.A.: Gibraltar Bibliography: a supplement, London, University, Institute of Commonwealth Studies, 1981; y (2) SHIELDS, Graham J.: Gibraltar, Oxford, Clio Press, 1987. Casi todo lo que se ha publicado sobre la plaza inglesa, y no sólo desde el punto de vista británico, español o gibraltareño, puede localizarse en The British Library integrated catalogue.

5 PACK, Stanley W. C.: Sea Power in the Mediterranean: a Study of the Struggle for Sea Power in the Mediterranean from the Seventeenth Century to the Present Day, London, Arthur Baker Limited, 1971, pp. 22-34/ 115-132.

6 Vid. Chipulina, Eric G.: «Gibraltar: The British Rock», en History Today, 30 (1980), pp. 25-31. 
bistorias de Gibraltar ${ }^{7}$, despertando en muchos casos un interés monográfico en el que la propaganda es un elemento clave ${ }^{8}$. Algo similar ha ocurrido con la reactivación del contencioso en los años sesenta del siglo pasado, cuando el estado de sitio pareció adueñarse de nuevo de la vida en la colonia y se actualizó como símbolo de un poder resistente?. Sin duda este último tema ha sido el que más se ha renovado con el paso del tiempo, produciendo una literatura de acuerdo con las nuevas circunstancias históricas en el marco legal de la Unión Europea $^{10}$.

Otro de los aspectos más tratados ha sido la identidad británica o britishness de los gibraltareños. En muchos casos este análisis se ha centrado en la fisono-

7 La cita a estas obras aparece en este apartado justificada por su carácter monográfico y, porque, a pesar de las matizaciones que puedan hacerse, ya sea en cuanto a la desigualdad en la erudición que presentan, ya sea en cuanto al contexto histórico en el que se producen, resultan prototípicas (la obra de M. Harvey por su carácter de historia ilustrada es la que más diferencia presenta en este sentido, asimilándose a las típicas publicaciones ilustradas gibraltareñas).GARRAT, Geoffrey T.: Gibraltar and the Mediterranean, London, Butler and Tanner ltd., 1939; Howes, Henry W.: The Story of Gibraltar, London, Philip \&Tracey, 1946; BRADFORD, Ernle: The History of a Fortress. Gibraltar, London, Bastford, 1971; Hills, George: El Peñón de la discordia. Historia de Gibraltar, Madrid, Editorial San Martín, 1974; JACKSON, William G. F.: The Rock of the Gibraltarians. A History of Gibraltar, Grendon, Northants, Gibraltar Books, 1990; HARveY, Maurice: Gibraltar a History, Staplehurst, Spellmount, 2000.

8 El folleto coetáneo de J. Drinkwater, A History of the Late Siege of Gibraltar (1781) suele considerarse el primer referente contemporáneo sobre este aspecto de la historia inglesa del Peñón, convirtiéndose en un clásico que en adelante tendría mucho predicamento en la literatura militar. No obstante, la utilidad militar de la Roca ya se había esgrimido en algunos opúsculos del siglo XVII que debieron actuar como acicate para la conquista. En cuanto a la Segunda Guerra Mundial, la «Operación Félix» o la contribución de Gibraltar al desembarco en el Norte de África (J.R. Thackrah), fueron objeto de interés preferente para un determinado tipo de literatura propagandística. Es frecuente hallar la referencia a la posición británica en el operativo «Torch» en obras de muy distinto tenor, estratégico-militar o político, enlazando con dos temáticas muy abordadas por la historiografía mundial: (1) La Guerra Civil española; y (2) el régimen de Franco durante la II Guerra Mundial y en la inmediata postguerra. Significante es el recuerdo a Gibraltar en CHURCHILL, Winston S.: La deuxieme guerre Mondiale. Paris, Librairie Plon, 1948-1954, pp.203-218 (II); у pp.202-227 (IV). El espionaje en la Roca constituye otro de los leit-motiv del período.

9 LAMBERT, David: op. cit. p. 206.

${ }^{10}$ El White Book de 1965 se identifica en España como referente, pero la preocupación inglesa por la situación legal de Gibraltar es anterior a la reactivación del contencioso durante el franquismo, como demuestra la obra de AвВOTт, Wilbur C.: An introduction to the documents relating to the international status of Gibraltar 1704-1934, [s.i.] Macmillan, 1934. Con perspectiva más actual tanto desde el punto de vista inglés como español: MORRIs, David S.: Britain, Spain and Gibraltar 194590: the eternal triangle, London, Routledge, 1992; GOLD, Peter: Gibraltar: British o Spanish?, London, Routledge, 2004; A stone in Spain's shoe. the search for a solution to the problem of Gibraltar, Glasgow, Liverpool University Press, 1994. En 2002 el periodista M. Leguineche haría uso del mismo tópico en Gibraltar. La roca en el zapato de España, Madrid, Espasa Calpe, 2002; IZQUIERDO SANS, Cristina: Gibraltar en la Unión Europea: consecuencias sobre el contencioso bispano-británico y el proceso de construcción europea, Madrid: Tecnos, 1996; GonZÁlez García, Inmaculada y DEL VALLE GÁlveZ, Alejandro: Gibraltar, 300 años, Cádiz: Universidad, 2004. 
mía e instalaciones militares de la plaza, relegando a la población autóctona ${ }^{11}$. Los gibraltareños durante mucho tiempo han sido contemplados con un «exotismo simpático» incluyendo sentimientos desde el extrañamiento por lo pintoresco hasta el desprecio más condescendiente. Las obras clásicas de J.D. Stewart y de G. Hills, publicadas en los momentos álgidos del contencioso, manifiestan un acusado contraste de identidades entre centro y periferia en la descripción de los naturales de la colonia. No obstante, en los títulos más recientes ha cambiado la perspectiva hacia una mayor empatía con la personalidad gibraltareña ${ }^{12}$. William G.F. Jackson, Gobernador Militar de la colonia entre 1978 y 1982 es autor de una de las mejores historias de Gibraltar ${ }^{13}$.

La historia de la colonia es, por tanto, una historia connotada, traduciéndose en una producción bibliográfica con muchas lagunas y que suele concentrarse en torno a cuatro grandes lugares comunes elegidos al servicio de la gloria del que fuera Imperio ${ }^{14}$ : El «Gran Asedio»; la Segunda Guerra Mundial; el contencioso con España y el carácter británico (Britishness) de la Roca y sus moradores. La fortuna del tópico en la enunciación de la ideología imperialista de un poder talasocrático explica el largo recorrido de la imagen del Gibraltar inexpugnable que, con algunas matizaciones, ha llegado hasta nuestros días ${ }^{15}$.

${ }_{11}$ A pesar de la temprana concesión del Estatuto colonial en 1830, es significativo que en la documentación oficial británica se haya continuado denominando a la colonia como fortress hasta 1970, vid. SePúlveda MuÑoz, Isidro: Gibraltar. la razón y la fuerza, Madrid, Alianza, 2004, p. 263. El estudio con perspectiva histórica de la arquitectura militar en la plaza ejemplificaría esta modalidad de análisis, vid. HugHes, Quentin, Strong as the rock of Gibraltar, Gibraltar, Exchange Publications, 1995; DiETz, Peter (ed.): Garrison: Ten British military towns, London, Brassey's Defence Publishers, 1986, pp. 177-200; The British in the Mediterranean, London, Brassey's Ltd, 1994.

12 Destacamos la reciente reflexión sobre la personalidad gibraltareña a partir de los factores materiales y espirituales que confluyen en ella de ARCHER, E.G.: Gibraltar, identity and Empire, Oxfordshire: Routledge, 2006.

${ }_{13}$ Es habitual hallar la conexión entre los autores y la colonia a través de un destino profesional, ya sea de índole militar o burocrático, el caso de Jackson resulta paradigmático.

${ }^{14}$ En general se echan en falta estudios académicos monográficos y, en particular, la incardinación desde el bifrontismo al que la interacción de Gibraltar con el territorio español aledaño obliga, de las diferentes realidades del Peñón desde el 4 de agosto de 1704. No obstante, habría que señalar la línea de investigación desarrollada sobre Historia de Gibraltar en la Universidad de Lancaster Community, society and identity in 19th and 20th-century Gibraltar (M. Blinkhorn Main Researcher), proyecto al que se adscriben dos dissertations sobre la burguesía gibraltareña en los siglos XIX-XX y el Gibraltar de los años comprendidos entre la II República y la Guerra Civil española respectivamente. En el ámbito de la Commonwealth son susceptibles de ser individualizadas iniciativas académicas como son los estudios sobre demografía y género desarrollados en la Toronto University de Canadá.

15 LAW, Alex: "Of navies and navels: Britain as a mental island», en Geografiska Annaler, Series B: Human Geography, 87 Issue 4, (2005), pp. 267-277. 


\subsubsection{El Gibraltar Gibraltareño}

«The culture of «loyalty» in Gibraltar is far more than anglophilic mimicry, but rather the selective appropriation and instrumentalization of imperial history, symbolism and myth to articulate local belonging» 16

Los autores gibraltareños (Benady, Ellicott, Finlayson, García o Palao) escriben desde la conciencia de su identidad Británica. Si reivindican una historia que liga sus destinos al del Imperio es porque ésta les confiere una personalidad diferenciada de la de sus «vecinos» ${ }^{17}$. La figura del Gobernador Militar de la plaza o la intensa relación con las British Armed Forces y, especialmente, con la Royal Navy son tópicos que han proliferado en la reconstrucción de un pasado colonial del que los campogibraltareños, en principio, habrían carecido ${ }^{18}$. La época Victoriana se ha tratado como un período predilecto, ya que su impronta en el urbanismo y las costumbres exhibirían la fisonomía más británica de la colonia. El crecimiento económico que se experimentó en esos años, sentó las bases para el desarrollo de una proto-sociedad civil, que en 1921 se vio recompensada con la institución del City Council. La Gran Guerra sirve, por tanto, de transición entre dos épocas que marcan los primeros pasos hacia el autogobierno dentro de un proceso político común en el ámbito colonial.

Pero la conciencia histórica gibraltareña ha trascendido la mera arrogación de la personalidad británica, adquiriendo un significado propio ${ }^{19}$. Así, la resistencia a los asedios del siglo XVIII además de consolidar una determinada auto-imagen del Imperio, fraguaría un rasgo del carácter de los habitantes de la plaza: la tenacidad ante un entorno hostil que define a la «closed -frontier generation», a la cual pertenecen quienes llevan las riendas políticas de Gibraltar en la actualidad ${ }^{20}$. En esta dirección la Segunda Guerra Mundial no representaría tanto el papel jugado por la Roca en la Operación Torch como la historia de un penoso exilio, concebido como un paso crucial hacia la afirmación identita-

${ }^{16}$ LAMBERT, David: p.218.

17 Vid. ARCHer, E.G.: p.25; desde el punto de vista local, GARCÍA, Joe, Gibraltar.The making of a people: the modern political history of Gibraltar and its people, Gibraltar, Medsun, 1994.

18 BenAdy, Tito M.: Gibraltar's Governors, Gibraltar, Calpe News, 1978; The Gibraltar Police 1830-1980, Gibraltar, Mediterranean Sun, 1980; The Royal Navy at Gibraltar since 1900, Lodge Hill, Liskeard, Cornwell, Maritime Books, 2004. ElLICOTT, Dorothy: Gibraltar's Royal Governor, Gibraltar, Museum Committee, 1981.

${ }_{19}$ Léase en este sentido el discurso de Peter Caruana, Ministro Principal de Gibraltar, con motivo del Tricentenario "A Proud Past and Confidence for the Future», Gibraltar Chronicle. 3 agosto 2004. http://www.chronicle.gi/archive2.php\#.

${ }^{20}$ ELLICOTT, Dorothy: From Rooke to Nelson, 1704-1805. 101 eventful years in Gibraltar, Gibraltar, Garrison Library, 1965; Bastion against aggression, Gibraltar, Gibraltar Society, 1968; Our Gibraltar: a short history of the Rock, Gibraltar, Museum Committee, 1975. 
ria, una vez sufrida en toda su crudeza la alteridad respecto a lo inglés ${ }^{21}$. De esta forma los gibraltareños comenzaron a pensar y escribir su historia a partir de la segunda postguerra mundial, cuando el bagaje de la experiencia traumática del exilio les impulsó a pensar sobre sí mismos, sin olvidar la amenaza que representó la política exterior de España al llevar su reclamación histórica a Naciones Unidas. En este apartado encontramos historias breves e ilustradas representativas de una población preocupada por su pasado, como primer argumento para la defensa de sus tesis en el contencioso. Con todo, la mirada gibraltareña sobre su historia es más compleja de la aquí esbozada ${ }^{22}$.

\subsubsection{El Gibraltar español}

Desde España la percepción colectiva sobre la colonia también ha mediatizado su estudio histórico. El mito de la inexpugnabilidad es sustituido por el de la vulnerabilidad. La conquista militar del Peñón, el Tratado de Utrech y sus reiterados incumplimientos se interpretan en clave de humillación nacional ${ }^{23}$. La relación entre Gibraltar, como tópico, y el nacionalismo español ha sido analizada por Isidro Sepúlveda, quien ha interpretado dos orientaciones en la reclamación: afirmativa en el «ejercicio total de soberanía»; y negativa, con un significado de Reconquista. En la primera orientación, podrían sentirse reconocidos sectores progresistas y, en la segunda, aquellos más enraizados en el pensamiento conservador y reaccionario, incluyendo en esta última corriente a la excesiva publicística franquista ${ }^{24}$. La historia de Gibraltar es la historia de una

${ }^{21}$ En torno a unos 16.700 gibraltareños fueron evacuados a Jamaica, Madeira, Londres y el Norte de Irlanda en un azaroso periplo que se inició en mayo de 1940. Experiencia traumática presente en la memoria de miles de gibraltareños con un impacto decisivo en el desarrollo de la sociedad civil gibraltareña de postguerra. El exilio y la «Operación Félix» son dos de los leits motivs de la memoria gibraltareña del período, cuyos principales exponentes los hallamos en las dos obras monográficas: FINLAYSON, Tom J.: The fortress came first: the story of the civilian population of Gibraltar during the Second World War. Grendon, Northernts, Gibraltar books, 1991; GARCíA, Joe: Operation Felix: Hitler's plan to capture Gibraltar, Gibraltar, Mediterranean Sun, 1982.

${ }_{22} \mathrm{El}$ interés de los llanitos por su historia adquiere tintes muy variados y la revista local Gibraltar Heritage Journal da buena cuenta de ello. Véanse, por ejemplo, los estudios de Tito M. Benady sobre los orígenes y evolución de la comunidad semita en la Roca o los de Sam Benady sobre la historia socio-sanitaria del Peñón.

${ }^{23}$ Delgado Bañón, Luis: Gibraltar 1704-2004. 300 años de desidia, humillación y vergüenza, Cartagena, Aglaya, 2004. El Capitán de navío e historiador naval narra la historia de Gibraltar durante el siglo XX, en la que los hitos más significados en la «desidia, humillación y vergüenza» habrían sido la erección de la verja en 1908 y construcción del aeródromo durante la guerra civil española.

24 SEPÚlveda MuÑOZ, Isidro: «Entre el tópico y la reivindicación: la instrumentalización de Gibraltar en el pensamiento conservador español», en Espacio, tiempo y forma (Historia Contemporánea), 8, (1995) pp.11-32; «Instrumentalización nacionalista del irredentismo: Gibraltar y el nacionalismo español», en Spagna Contemporanea, 9 (1996), pp. 79-101; Gibraltar...op.cit. pp. 270-280. 
reclamación colectiva. Por eso, las últimas aportaciones con motivo del Tricentenario de su conquista no han perdido de vista el horizonte legal, de tal modo que Gibraltar encarna «la historia local, la historia de las disputas por su posesión y la historia de aquellos que la han conseguido» en «la sucesión de acontecimientos que han motivado el secular contencioso entre España y Gran Bretaña» ${ }^{25}$. No obstante se identifican aproximaciones al estudio histórico del Peñón que no pueden ser encasilladas en la literatura de la reivindicación.

Los Congresos Internacionales del Estrecho celebrados en Ceuta en la segunda mitad de los años 80 del siglo $\mathrm{XX}^{26} \mathrm{y}$, sobre todo, las investigaciones de Rafael Sánchez Mantero sobre diplomacia y contrabando en el siglo XIX ${ }^{27}$ son ejemplos de un empeño específico por el estudio de la historia de Gibraltar. En cuanto a las temáticas, el valor militar de la plaza y el origen de sus habitantes, históricamente considerados en términos de "pesudopoblación» ${ }^{28}$, han destacado en un interés por lo general «a remolque» del inglés: los asedios y la Segunda Guerra Mundial se repiten como dos de los tópicos más frecuentes ${ }^{29}$. Además, la «Cuestión de Gibraltar» ha sido analizada dentro de las relaciones bilaterales hispano-británicas en coyunturas claves del siglo XX, desde el 98 a la entrada de España en la Alianza Atlántica y la entonces Comunidad Europea ${ }^{30}$. Los aspectos

${ }_{25}$ Vid. SePÚlveda MuÑOZ, Isidro: Gibraltar..op. cit., . p.14. Entre las aportaciones más recientes cabría destacar: desde el ámbito periodístico LEGUINECHE, Manuel: op. cit.; desde el punto de vista jurídico con la incardinación del contencioso hispano-británico en el proceso de construcción europea, IZQUIERDO SANS, Cristina: op. cit.; y, con motivo del tricentenario: SEPÚlvEDA MUÑOZ, Isidro: Gibraltar...op.cit.; e GonZÁlez García, Inmaculada y Del VAlLE GÁlveZ, Alejandro: op. cit.

26 Ripoll Perelló, Eduardo: (ed.), Actas del I Congreso Internacional del Estrecho de Gibraltar, Ceuta, UNED, 1987; Actas del II Congreso Internacional del Estrecho de Gibraltar, Ceuta, UNED, 1990.

27 SÁNCHEz MANTERO, Rafael: Estudios sobre Gibraltar: política, diplomacia y contrabando en el siglo XIX, Cádiz, Diputación provincial, 1989. En la actualidad R. Sánchez Mantero dirige el proyecto de investigación «Gibraltar: de fortaleza a colonia» (HUM2005-00858)

${ }^{28}$ La obra de referencia habría sido: RiCO, Gumersindo: La población de Gibraltar, Madrid, Editora Nacional, 1967.

29 Calvo Poyato, José: «Gibraltar, nuevas aportaciones: la financiación y gastos del asedio de 1704-1705», en Cuadernos de investigación histórica, 186 (10), pp. 165-182. La Operación Félix y las redes de espionaje y contraespionaje en el Campo de Gibraltar han suscitado gran curiosidad en España, avivada ésta por las expectativas creadas en dicha coyuntura sobre la recuperación del Peñón: JATO, David: Gibraltar decidió la guerra, Barcelona, Acervo, 1978, título mediatizado por un determinado prisma ideológico sobre Gran Bretaña y con cierto compromiso hacia la memoria de Serrano Súñer; más reciente y aséptica es la obra de EsCuADRA SÁnCHEZ, Alfonso: A la sombra de la Roca. La Segunda Guerra Mundial desde el Campo de Gibraltar, Córdoba, Caja Sur, 1997. Muy interesante resulta la visión poliédrica que nos ofrece este último autor sobre la Segunda Guerra Mundial desde el Campo, tomando como referencia los avatares de la Roca. La propuesta de análisis integrador de las distintas realidades local-comarcal, regional, nacional e internacional constituye otro de los hallazgos de la obra. Una aportación muy reciente es la de TéLlez RuBiO, Juan José: Gibraltar en el tiempo de los espías, Sevilla, Fundación José Manuel Lara, 1995.

30 Aludiremos a títulos cuyos autores, historiadores reputados por su especialización en política exterior española, contextualizan desde los albores del siglo XX la problemática en torno a Gibral- 
geoestratégicos han estado también muy presentes ${ }^{31}$. Por último, debemos mencionar los trabajos de divulgación de la Mancomunidad de Municipios del Campo de Gibraltar, con la publicación de La revista de estudios campogibraltareños, Almoraima que propone la recuperación de una memoria colectiva, en la que la presencia británica no se toma tanto como un elemento traumático sino como un rasgo cotidiano del paisaje local ${ }^{32}$.

La historia contemporánea de la colonia inglesa es, por tanto, una historia con significados añadidos desde todos los puntos de vista. De ahí que la mirada desapasionada y aséptica indispensable en el historiador no haya encontrado en Gibraltar un campo atractivo para la investigación. Como hemos expuesto, la Primera Guerra Mundial constituye un período que pasa desapercibido, situándose entre la incógnita y la anécdota. Sin embargo, las razones de este vacío no se agotan en el «problema general» que presenta una historiografía sobre el Gibraltar contemporáneo, sino que además tiene un origen específico en la revisión crítica de la Gibraltar Tradition durante los años del «climaterio»33 y que, a continuación, trataremos con mayor detenimiento.

\subsection{Gibraltar 1914-1918: un caso particular}

\subsubsection{La Gibraltar Tradition: una revisión a la baja}

En el transcurso del siglo XIX el valor naval de la plaza empezó técnicamente a cuestionarse en ámbitos militares y políticos. Las ventajas que para el

tar: ROSAS LEDEZMA, Enrique: «Las relaciones hispano-británicas a comienzos del siglo XX: los caminos del entendimiento", en Revista de Estudios Internacionales 3 (1980), pp. 703-725; JOVER ZAMORA, José María: «Gibraltar 1898», en Cuadernos de Historia Contemporánea 9 (1988), pp. 189-196; DE LA TORRE, Rosario: Inglaterra y España en 1898, Madrid, Eudema, 1988, pp. 249-286; PEREIRA CASTAÑARES, Juan Carlos: «La cuestión de Gibraltar. (Cambios, ofensivas y proyectos en la búsqueda de un acuerdo hispano-británico en el primer tercio del siglo XX)», en VILAR, Juan Bautista: Las relaciones internacionales en la España Contemporánea, Murcia, Universidad, 1989, pp. 245-268; y PORTERO, Florentino: «El contencioso gibraltareño 1936-1991», en Historia 16187 (1991), pp. 60-72.

31 UXÓ PALASÍ, José: et alii, Estudios sobre Gibraltar, Madrid, Instituto de Cuestiones Internacionales y Política Exterior, 1996; Valoración estratégica del Estrecho de Gibraltar, Madrid, Ministerio de Defensa, 1998. Otras aportaciones dignas de ser reseñadas aunque se desvinculan de la institución castrense: Astillero Ramos, José Manuel (ed.): Historia del paso del Estrecho de Gibraltar, Cádiz, SECEGSA, 1995; CestinO, Joaquín: El Estrecho. Treinta siglos de Historia en Gibraltar, Tánger, Tarifa, Ceuta y Algeciras, Málaga, Arguval, 2004.

32 Editada semestralmente, Almoraima, sirve de soporte para la difusión de las comunicaciones que se presentan a las distintas Jornadas organizadas por el Instituto de Estudios Campogibraltareños.

33 A partir de 1873 la economía británica entró en la fase denominada «Climaterio», terminología referida a la imposibilidad para «crecer más». Gran Bretaña como potencia industrial y comercial fue gradualmente perdiendo peso a favor de los Estados Unidos y Alemania. A pesar de la tendencia, gracias a su vasto mercado colonial, mantuvo su posición mundial de hegemonía hasta después de la Primera Guerra Mundial, cuando los efectos del «Climaterio» fueron internacionalmente perceptibles 
desarrollo portuario representaban enclaves de mayor superficie, como Malta o Chipre y, sobre todo, los avances en la artillería, pusieron de manifiesto que la Gibraltar Tradition sólo era propaganda. En la época dorada del positivismo no tenían cabida mitos ni leyendas.

Sin embargo, la presencia militar en el Estrecho de Gibraltar siguió considerándose vital para los intereses del Imperio. Un canje a España de Gibraltar por Ceuta se barajó como una solución sencilla a la par que idónea, la ensenada en la que esta última se situaba ofrecía condiciones más favorables para su defensa. Richard Congreve, uno de los padres del positivismo inglés, se hizo eco de esta propuesta en $1857^{34}$. La idea tuvo éxito y fue esgrimida en numerosos editoriales y artículos, desatando una polémica que, por las implicaciones emocionales colectivas generadas en torno a Gibraltar, llegó a discutirse políticamente al más alto nivel. La difusión en 1882 de un editorial del Spectator favorable a la permuta, "Is Gibraltar worth Keeping?", salpicó al entonces premier William Ewart Gladstone ${ }^{35}$. El arraigo del «Gibraltar inglés» en el discurso imperialista británico, interiorizado tanto por conservadores como por liberales, hizo inviable cualquier negociación bilateral en términos de devolución de la plaza. Independientemente de los juicios técnicos, la creencia popular de Gibraltar como la llave del Mediterráneo siguió siendo «tan firme como el Peñón» ${ }^{36}$.

El Gobierno inglés puso en marcha, justo en esos años, un costoso programa de remodelación de las infraestructuras de Gibraltar que suscitó numerosas críticas. Entre ellas, destacó, por sus consecuencias políticas, el opúsculo del parlamentario y publicista Thomas Gibson Bowles, Gibraltar a National Danger, de gran repercusión nacional e internacional ${ }^{37}$. La cuantía de los fondos movilizados para la construcción y ampliación de diques, más de cinco millones de libras aconsejaron el nombramiento de una comisión parlamentaria — de la que formó parte Bowles - para analizar sobre el terreno los riesgos a los que aludía el panfleto. El peligro potencial que España representaba para Gibraltar,

${ }^{34}$ Congreve, Richard M.A.: Gibraltar; or the Foreign Policy of England, Londres, Trübner and Co., 1864 ( $2^{\mathrm{a}}$ ed.).

35 Gladstone: estadista liberal, fue primer ministro en cinco ocasiones durante el ultimo tercio del siglo XIX, (1868-1874; 1880-1885; 1886; 1892-1894) turnándose con los conservadores Benjamin Disraeli y el Marqués de Salisbury. LARsonneur, Bathilde: Histoire de Gibraltar, Paris, Presses Universitaires de France, 1955, p. 84.

${ }^{36}$ Hills, George: op. cit., p.68. A pesar de que la opinión pública difícilmente aceptaría el canje, continuaron divulgándose artículos favorables al mismo en publicaciones como The Fortnightly Review, cit. BALlesteros, Ángel: Los contenciosos de la política exterior de España, Córdoba (Argentina), Lerner, 1998, p. 61

37 BOwLes, Thomas G.: Gibraltar. Un peligro nacional, traducido del inglés por Arturo O'Neill de Tyrone, Madrid, [s.n.], 1901, pp.12-29. Thomas Gibson Bowles (1841-1922) periodista que comenzó su carrera en el Morning Post en 1866, fundador de las revistas The Lady y en su versión inglesa Vanity Fair. En 1892 fue elegido Miembro del Parlamento por el Partido Conservador, continuando en su escaño hasta 1906. En 1910 volvió brevemente a la Casa de los Comunes como liberal. Pasaba frecuentemente sus vacaciones en Algeciras, donde murió siendo enterrado en Gibraltar. 
ya fuese como aliada de una potencia rival o desde la incapacidad para mantener su estatus neutral en caso de una guerra en la que Inglaterra se viese involucrada, constituía la principal inquietud ${ }^{38}$. Sin duda los acontecimientos internacionales ocurridos en 1898 debieron sugestionar al político a la hora de calibrar las amenazas que existían sobre la posesión. Por un lado, los frustrados trabajos españoles de artillado en Sierra Carbonera y, por otro, la rivalidad con Francia, que había estado a punto de estallar en Fashoda, levantaron todo tipo de suspicacias alrededor de la seguridad del Peñón, temiéndose una reedición de las alianzas que en el pasado pusieron en peligro la continuidad de la presencia inglesa ${ }^{39}$. El intento de arreglo franco-español sobre Marruecos en 1902 pareció confirmar los temores de Bowles, que volvió a reiterarse sobre el "peligro nacional» que acechaba a Gibraltar ${ }^{40}$. Inglaterra se jugaba algo más que un mal negocio. La conservación de la plaza se expresó entonces en términos de «Seguridad Nacional». La pérdida del Peñón serviría de acicate a las potencias rivales para discutirle a Gran Bretaña un poderío marítimo que habría visto desaparecido uno de sus máximos emblemas. No importaba que la Roca no fuese inexpugnable siempre que continuase en manos inglesas: "Gibraltar, por consiguiente, no es en modo alguno por sí mismo la llave del Mediterráneo; no es más que el sitio en que está colgada la llave» ${ }^{41}$.

Sin embargo la posibilidad de un ataque francés contra Gibraltar fue perdiendo fuerza paralelamente a la consolidación de la Entente Cordial entre Francia y Gran Bretaña. De hecho, en estos años previos a la Primera Guerra Mundial, la plaza recuperó valor estratégico al convertirse en el centro de operaciones del Almirantazgo en el Mediterráneo, cuyo traslado se produjo desde Malta en una fecha tan señalada como 1906, después de la Conferencia de Algeciras. La concentración de la flota mediterránea en la base del Peñón permitía cubrir con mayor solvencia las necesidades planteadas tanto en el Mediterráneo como en el Atlántico ${ }^{42}$. En la primavera de 1907 se produjo un intercambio de notas entre España e Inglaterra con objeto de hacer público el buen estado de las relaciones entre ambas naciones ${ }^{43}$, llama la atención que el

38 Ibid, p. 28.

39 Rosario de la Torre ha explicado la preocupación diplomática por Gibraltar en este contexto; DE LA TORRE, Rosario: op. cit.; «La crisis de 1898 y el problema de la garantía exterior» en Hispania 162 (1986), pp. 115-164.

40 Bowles, Thomas G.: Gibraltar and the Ministry, a Continuation of the Store of a National Danger, London, 1903, cit. en BALLESTEROS, Ángel: op. cit., p. 61.

41 Bowles, Thomas G.: Gibraltar a National...op. cit., p. 12.

42 Halpern, Paul G.: op. cit., p. 6.

43 Sobre las «Declaraciones de Cartagena» vid. ROSAS LEDEZMA, Enrique: «Las «Declaraciones de Cartagena» (1907): Significación en la política exterior de España y repercusiones internacionales», Cuadernos de historia moderna y contemporánea 2 (1981), pp. 213-229; DE LA TORRE DEL RÍO, Rosario: "Los acuerdos anglo-hispano-franceses de 1907: una larga negociación en la estela del 98», Cuadernos de la Escuela Diplomática, 1 (1988), pp. 213-229; GARCÍA SANZ, Fernando: Historia de las relaciones entre España e Italia. Imágenes, comercio y política exterior, Madrid, CSIC, 1994, pp. 289-328; 
único resultado tangible del gesto diplomático fuera la aceptación española del statu quo Mediterráneo, con el abandono de facto de la reclamación histórica sobre Gibraltar. La orientación de la política exterior española hacia la Entente fortaleció la posición inglesa en cuanto alejó a España de un posible entendimiento con Alemania que en 1914 pudiese amenazar el Peñón.

\subsubsection{Cañones frente a submarinos}

Aunque Gibraltar continuó conservando toda su utilidad estratégica a principios del siglo XX, el debate precedente sobre su vulnerabilidad socavó considerablemente su imagen. Así, según una nueva lógica en el discurso, uno de los valores principales de la posesión radicaba en su función propagandísti$\mathrm{ca}^{44}$. Esto explicaría el escaso interés despertado por la historia de la colonia entre 1914 y 1918, observándose una tendencia deconstruccionista de la Gibraltar Tradition que habría influido a posteriori en los autores ${ }^{45}$.

La colonia es presentada en esos años como un escenario de retaguardia en el que «la realidad era inferior al mito» ${ }^{46}$. La bibliografía ha incidido sobre las debilidades que la posición manifestó: ineficacia ante los movimientos de submarinos enemigos en el área del Estrecho; menos instalaciones en comparación a las de otros enclaves portuarios; lejanía del teatro de operaciones en el Mediterráneo Oriental; y dependencia operativa de la neutralidad española ${ }^{47}$. En

NiÑo RodrígueZ, A.: «Política de alianzas y compromisos coloniales para la «regeneración» de España en el siglo XX», en TUSELL, Javier, AviLÉs, Juan y PARDO Rosa: La política exterior de España en el siglo XX, Madrid, UNED-Biblioteca Nueva, 2000, pp. 31-94; «El Rey Embajador. Alfonso XIII en la política internacional», en Alfonso XIII. Un político en el trono, MORENO LUZÓN, Javier: Madrid, Marcial Pons, 2003, pp. 241-267.

${ }^{44}$ A la altura de 1914 Gibraltar disponía de cuatro diques y, de ellos, sólo dos secos habilitados para grandes buques. Por el contrario, Malta contaba con dos diques flotantes y cuatro diques secos, tres de estos últimos para navíos de gran calado, cfr. Revista General de Marina 76 (1915) p. 91.

${ }_{45}$ Esta tendencia puede identificarse con bastante unanimidad en los autores y no sólo en los británicos, vid. HerRmANN, Gerhard: Gibraltar, puerta del Mediterráneo, Santander, Cultura Española, 1938, pp. 119-127; SCHULZ, P.A.-Wilmersdorf: Gibraltar Terre Spagnole, Paris, Les Editions de France, 1941, pp. 25-28; y LARSONNEUR, Bathilde: op. cit., pp. 82-93.

${ }^{46}$ HiLLs, George: op. cit. p. 479; «Furthermore, there was the general public's emotional, albeit somewhat irrational, attachment to the place — "As safe as the Rock of Gibraltar's was not just and idle phrase», en HARVEY, Maurice: op. cit., p. 129.

47 El mito continuó funcionando con eficacia a efectos de propaganda, como lo prueban los paralelismos que entre Gibraltar y posiciones en lid en el escenario farragoso del Mediterráneo Oriental fueron establecidos: ganar alguna de estas posiciones implicaba una superioridad sobre el adversario análoga a la conseguida por el Imperio en el Mediterráneo Occidental con la posesión de Gibraltar «The Achi Baba Barrier. A «small Gibraltar» en The Times, 22 de junio de 1915, p.8. De igual forma pareció funcionar en el caso alemán, hallándose las referencias que reforzaban este valor simbólico del lado inglés en el Times, «The German Gibraltar», 30 de noviembre de 1914, p.7; en el $A B C$, «Mirando a la guerra. Gibraltar (I-II)», 31 de diciembre de 1914, pp. 6-7 y 4 de enero de 
resumidas cuentas: «la guerre de 1914-1918 avait mostré la faiblesse de cette position» ${ }^{48}$. Desde este punto de vista, durante la contienda se habría vivido una situación de aparente cotidianidad, Gibraltar «llegaría a la paz sin ningún signo evidente de haber estado alguna vez activamente comprometida en una guerra» ${ }^{49}$. Tan sólo la llegada masiva de soldados heridos en los Dardanelos con el consiguiente problema sanitario creado en los hospitales civil y militar, la formación del Gibraltar Volunteer Corps para ayudar en distintas tareas cívicas y la intensificación de la actividad en sus muelles habrían distorsionado la «normalidad» imperante en esos años ${ }^{50}$. Pero, a nuestro juicio, suelen pasarse por alto dos hechos que forzosamente debieron de tener un impacto decisivo sobre el día a día en la base y a los que no se les ha concedido suficiente importancia ${ }^{51}$ : en abril de 1917 Gibraltar fue elegido como centro del sistema de convoyes y en septiembre de ese mismo año se estableció su uso conjunto aéreo y naval con los Estados Unidos. Estos hechos además de traducirse en un espectacular incremento de la actividad portuaria acelerando los ritmos vitales en la colonia, vendrían a contradecir la idea arraigada de que «Gibraltar played no major active role in the First World War» ${ }^{52}$.

Aunque no se pudo impedir el acceso de los sumergibles alemanes al Mediterráneo $^{53}$, las decisiones tomadas por el Almirantazgo durante la guerra nos hacen pensar que el enclave debió de cumplir sobradamente con las expectativas depositadas como nudo de comunicaciones navales y centro de redistribución de mercancías en el Mediterráneo, proporcionando además un escenario privilegiado para la cooperación aliada. De ahí que se eche en falta algún trabajo sobre Gibraltar por parte de una tradición historiográfica tan consolidada en el estudio de ambas guerras mundiales como la británica ${ }^{54}$. El arraigo de un estereotipo revisionista sobre Gibraltar, de signo contrario al de la inexpugnabilidad, está en la raíz de un vacío que no puede ser justificado por más tiempo.

1915, pp. 3-4; o en el diario comarcal de carácter aliadófilo El Campo de Gibraltar, «El Gibraltar del Báltico», 1 de noviembre de 1917, p. 1.

${ }^{48}$ LARSONNEUR, Bathilde: op. cit., p. 90

49 "Gibraltar slid into the peace without any real signs that she had ever been engaged in a war», en BRADFORD, Ernle: op. cit., p. 180.

${ }_{50}$ JACKSON, William G.F.: op. cit., p. 265; HARveY, Maurice: op. cit., p. 132; BENADY, Tito: op. cit. p. 10; y HiLLs, G.: op. cit., pp. 481-485.

${ }^{51}$ Herrmann, Gerhard: op. cit., p. 127, Hills, George: op. cit., p. 480, Larsonneur, Bathilde: op. cit., p. 90.

52 HaRvey, Maurice, op. cit. p. 130

${ }_{53}$ El retorno en la última de guerra a través del Estrecho de Gibraltar de a puertos germanos de trece de quince submarinos, habría sido la «mejor prueba» que invalidaría el carácter decisivo de la base en el control del acceso y salida por este desfiladero marítimo. El dramático hundimiento del Britannia el 9 de noviembre de 1918 frente al Cabo Trafalgar por el $U$-50 redundaría en esta opinión. Vid. GARRATT, Geoffrey T.: op. cit. p. 189.

${ }^{54}$ Halpern, Paul G.: op. cit., p. 395. Este autor aun refiriendo el papel decisivo de Gibraltar en el sistema de convoyes, no profundiza en la cuestión. 


\section{GiBRALTAR Y SU CAMPO 1914-1918. UNA PROBLEMÁTICA RELACIÓN CON LA NEUTRALIDAD OFICIAL DE ESPAÑA}

A lo largo del siglo XIX, como ya hemos señalado, se especuló mucho sobre el papel estratégico que Gibraltar habría podido jugar en caso de que Gran Bretaña se hubiese visto envuelta en una guerra. En ese horizonte hipotético una de las principales preocupaciones fue la orientación que España pudiese adoptar como beligerante o neutral, así como su capacidad, en el último de los casos, para hacerla valer frente a terceros. La declaración de la neutralidad española en los primeros días de agosto de 1914 despejó muchas incógnitas, pero no todas 5 . ¿Requirieron los planes del Estado mayor británico para Gibraltar algo más que la estricta neutralidad?

La política de benevolencia de los diferentes gobiernos españoles hacia la colonia constituyó un punto de apoyo imprescindible para las operaciones de los aliados en el Mediterráneo occidental. Atendiendo a las funciones de Gibraltar como a) puesto de control de la navegación marítima y comercial en el Estrecho, b) base del sistema de convoyes y c) centro neurálgico del Almirantazgo para fines de estrategia general en la Península Ibérica y el norte de África, estructuraremos el análisis desde tres ámbitos que — por intervención o inhibición- exigieron la colaboración de la administración española en el Campo de Gibraltar: primero, las acciones de los navales ingleses; segundo, el suministro de agua y víveres a Gibraltar; y tercero, el control de los movimientos de los espías alemanes.

\subsection{Las aguas jurisdiccionales de la bahía de Algeciras}

La Bahía de Algeciras ha sido un escenario clave para el estudio de la neutralidad española tanto en la Primera como en la Segunda Guerra Mundial puesto que la puesta en valor de Gibraltar como base naval ha conllevado flagrantes vulneraciones de las aguas jurisdiccionales españolas ${ }^{56}$. En este apartado mostraremos algunos ejemplos de las mismas para la Primera Guerra Mundial, prestando especial atención a la actitud de los sucesivos gobiernos españoles.

\subsubsection{Las dos caras del sistema de listas: La Ybarra y Cía y La Compa- ñia Valenciana de Vapores de África}

Una de las labores más importantes que realizó el staff naval de Gibraltar durante la guerra fue controlar las rutas y movimientos comerciales de las na-

\footnotetext{
ss Gaceta de Madrid 07/08/1914 N 219, Sección Política:-ordenando a los súbditos españoles la más estricta neutralidad en el conflicto europeo, p. 308

56 Respecto a la tradicional indefinición de la postura española en torno a las aguas jurisdiccionales inglesas, vid. GONZÁLEZ GARCíA, Inmaculada: «La bahía de Algeciras y las aguas españolas», en GONZÁlez DEL VAlLE, Alejandro e GONZÁLEZ García, Inmaculada (eds.): op. cit., pp. 211-236.
} 
vieras españolas, destacando la cuantía y la precisión de la información extraída para la elaboración de listas negras. El éxito del sistema de vetos («White list» / «Black list») para "persuadir» a las compañías españolas de que trabajaran al servicio del Almirantazgo se debió, en gran medida, al jefe del Estado mayor de los navales en Gibraltar y responsable del espionaje británico en España, el mayor de Infantería Ligera de Marina - a partir de 1916 - teniente coronel, Charles Julian Thoronton ${ }^{57}$. Sus informes, una vez remitidos a Londres, tenían la última palabra sobre la inclusión de las firmas en una lista u otra.

Pero los británicos no se limitaron a recabar información desde su privilegiado observatorio de Gibraltar, también actuaron aprovechando las ventajas que la base les ofrecía para realizar escaramuzas en aguas jurisdiccionales españolas contra barcos sospechosos de cargar contrabando de guerra. Los abordajes contra los mercantes de navieras que no estuviesen libres de la más leve sospecha de comerciar con el enemigo, se saldaron con una abrumadora tutela de los ingleses en el sector. La estrategia aplicada no fue otra que la del palo y la zanahoria. La cara «amable» del chantaje consistía en conceder facilidades para el suministro de carbón mineral, en Gibraltar o en puertos españoles, a las compañías incluidas en la «lista blanca». Las presiones sobre la Ybarra y Cía., en el verano de 1915 con el apresamiento de sus vapores en ruta de Málaga a Sevilla, ejemplificaron esa forma de imponer bajo cuerda la prestación de tonelaje a la causa aliada ${ }^{58}$. Estos procedimientos colocaron en más de un aprieto al Gobierno español, obligando al ministro de Estado de turno a pedir explicaciones al embajador de Inglaterra ${ }^{59}$. Arthur Hardinge, para legitimar estas acciones, aunque paradójicamente sin reconocer los hechos, aludía a informes de los servicios secretos de su país sobre la supuesta tendencia germanófila de los dueños de las navieras o, en su defecto, de los miembros del Consejo de Administración ${ }^{60}$. El Marqués de Lema, como responsable de Estado en los dos gabinetes presididos por Eduardo Dato, tuvo incluso que jugar el incómodo papel

57 Charles Julian Thoronton, en ausencia de agregado naval inglés hasta la primavera de 1918, fue el interlocutor válido con los agregados navales del resto de los países aliados, en ELIZALDE PÉREZ-Grueso, $\mathrm{M}^{\mathrm{a}}$ Dolores: «Los servicios de inteligencia británicos en España durante la Primera Guerra Mundial», en Revista de Historia Militar XLIX (2005), pp.237-258; Sobre Gibraltar como cuartel general del espionaje británico en la Península Ibérica y el Norte de África, ANDREW, Christopher: The making of the British Intelligence Community, London: Heinemann, 1985, pp. 115-119.

${ }^{58}$ En Archivo del Ministerio de Asuntos Exteriores en Madrid (en adelante AMAEM), leg. H2491 Serie Gran Bretaña (en adelante SGB) 1911-1926, particular d. s/n, Tomás de Ybarra al Marqués de Lema, Sevilla, 17 de julio de 1915. Tomás de Ybarra informó de la detención improcedente del vapor "Cabo Cervera» por el servicio de vigilancia naval inglés en su ruta de Málaga a Sevilla, pasada Punta Carnero y, por tanto, en aguas jurisdiccionales españolas.

59 Fernando Tovía, representante de la Trasatlántica confirmaba estas presiones, en íbid, leg. H1346 Correspondencia Embajadas y Legaciones Alemania 1911-1916 (en adelante CELA). Notas Verbales, particular, Fernando Tovía, Compañía Trasatlántica, al Ministro de Estado, 28 de agosto de 1916.

${ }^{60}$ Íbid., leg. H2491 SGB 1911-1926, privado d. s/n, el Embajador de Gran Bretaña en Madrid en España al Ministro de Estado, Madrid, 21 de julio de 1915. 
de correa de transmisión de los deseos del Foreign Office a particulares, una situación muy delicada cuando afectaba a amigos políticos como eran los Yba$\mathrm{rra}^{61}$. Ni siquiera las buenas relaciones de los empresarios y políticos sevillanos con Eduardo Dato, a cuyo gobierno prestaron servicios como la inclusión del Puerto de Lisboa en las líneas de la naviera en $1915^{62}$, sirvieron de algo más que para que Lema se limitara a observar las contradicciones de la estrategia inglesa con los objetivos que ésta perseguía ${ }^{63}$ :

«Usted convendrá conmigo, mi querido Embajador, en que por mucho que sea el germanofilismo de los Señores Ybarra no altera la situación ni justifica la vejación que representa para la bandera española el constante registro de buques que la arbolan y á cuyo amparo se dedican á un tráfico natural y corriente. Y yá en el terreno puramente confidencial y amistoso en que nos encontramos me permitiré agregar que no creo sea ese el procedimiento más adecuado para desarraigar de los Señores Ibarra los sentimientos germanófilos, si es que en realidad los tienen.»

Los comportamientos hostiles de las patrulleras de Gibraltar contra intereses privados en aguas jurisdiccionales retaron continuamente la posición oficial del Ejecutivo, sin que éste mostrara capacidad ni voluntad de ponerles fin. Sin embargo, frente a los casos de Ybarra y Cía o la Compañia Trasatlántica que terminaron aceptando como inevitables las intromisiones, otras navieras abrazaron la causa inglesa como una gran oportunidad de hacer negocio. La Compañía Valenciana de Vapores de África fue un ejemplo paradigmático de esto último. El dueño de esta compañía, senador por el Partido Liberal en Valencia y representante de la poderosa Asociación de Navieros del Mediterráneo, José Juan y Dómine, no sólo mantuvo comunicación al más alto nivel con «sus amigos» de Gibraltar también con Arthur Hardinge ${ }^{64}$. En el otoño de 1915 el Cónsul español en la colonia daba cuenta a Lema de «los importantes servicios» que dicha naviera debía estar realizando para los británicos, puesto que las ventajas concedidas en el despacho de carbón a sus buques «resultaban privilegios sobre todas las demás compañías incluso sobre las inglesas» ${ }^{65}$. En el estado actual de la investigación no conocemos en detalle las prestaciones que La Compañia Valenciana de Vapores de África pudo realizar para el Departamento de Inteligencia

\footnotetext{
${ }^{61} \mathrm{Ibid}$, leg. H2509 Política España-Gran Bretaña 1916-1919, nota d. s/n, el Ministro de Estado al Embajador británico, Madrid, 18 de octubre de 1917.

${ }^{62}$ Carta de Eduardo Dato a Tomás Ybarra González, 1 de noviembre de 1915, en Sierra AlonSO, María: La familia Ybarra. Empresarios y políticos, Sevilla, Muñoz Moya y Montraveta, 1992, p. 47.

${ }^{63}$ En AMAEM, leg. H2491 SGB 1911-1926, confidencial (minuta), el Ministro de Estado al embajador de Gran Bretaña en Madrid, San Sebastián, 26 de julio de 1915.

${ }^{64}$ Íbid, d. s/n, el Cónsul de España en Gibraltar al Ministro de Estado, Gibraltar, 8 de noviembre de 1915.

${ }^{65}$ Íbid, d. s/n, el Cónsul de España en Gibraltar al Ministro de Estado, Gibraltar, 21 de noviembre de 1915 .
} 
Naval, pero el transporte de correos y pertrechos para los aliados desde la Península al Norte de África no parece que fuera un asunto ajeno a sus actividades. La colaboración debió de resultar cara a «los amigos ingleses» que favorecieron los intereses de Dómine siempre que tuvieron ocasión ${ }^{66}$.

\subsubsection{Los conflictos con la Compañía Arrendataria de Tabacos y la ad- ministración local}

Los excesos de los patrulleros de Gibraltar sobre las navieras españolas no originaron las únicas situaciones comprometedoras para los gobiernos españoles. La injerencia desde la colonia en la represión del contrabando desencadenó frecuentes altercados con los guardacostas de la Compañía Arrendataria de Tabacos (CAT). La protección de las lanchas inglesas a la actividad contrabandista de Juan March, llegando incluso a actuar como escolta de sus faluchos, fue un motivo de desencuentro entre las Comandancias de Marina locales y la política de «mirar hacia otro lado» del Gobierno. Pero, ¿por qué los marinos ingleses dieron cobertura a los intereses del mallorquín cuando sus tratos con alemanes eran de sobra conocidos? Al contrario de lo que el propio March hizo creer, lo cierto es que Verga fue un hombre de confianza de Thoroton, trabajando al servicio del Almirantazgo no sólo durante la Primera Guerra Mundial, sino también en la Segunda. La colaboración de March fue vista con muy buenos ojos desde Londres, especialmente por el jefe del Departamento de Inteligencia Naval, el Almirante Hall ${ }^{67}$.

Son muchos los ejemplos de las intromisiones inglesas en la represión del contrabando en la bahía de Algeciras, pero destacamos uno muy significativo sobre la actitud de la administración española y que ocurrió en la madrugada del 19 de agosto de 1916, cuando una lancha frustró la persecución de una de las embarcaciones de March con intención de alijar tabaco ${ }^{68}$. El informe del

\footnotetext{
${ }^{66}$ Archivo Romanones, legajo 83, expediente 9, pieza 3, José Juan y Dómine al Conde de Romanones, Madrid, 11 de febrero de 1916.

${ }^{67}$ Vid BeEsLY, Patrick: Room 40. British Naval Intelligence 1914-1918. Oxford, Oxford University Press, 1984, pp. 190-191; William, James: (Admiral), The eyes of the navy. A Biographical Study of Admiral Sir Reginald Hall. London, Methuen, 1956, pp. 107-108; DEACON, Richard: British Secret Service. Glasgow, Collins, 1991 ( $1^{\mathrm{a}}$ ed. 1969), pp. 209-211; DiXon, Arturo, Señor monopolio o la asombrosa vida de Juan March, Planeta, Barcelona, 1985, p. 14-38; El que el famoso contrabandista, conocido también como Verga, estuviese detrás de la creación de la Transmediterránea nos aporta un dato a tener muy en cuenta que lo conecta con José Juan y Dómine, uno de los armadores fundadores de la naviera junto a Vicente Ferrer, Joaquín Tintoré y Enrique García en noviembre de 1916. Esto contrasta con la colaboración activa que con los intereses alemanes se suele atribuir a March, sobre todo, en lo referente al abastecimiento de submarinos, vid. GARRAT, Geoffrey T.: op. cit., p.190; BRADFORD, Ernle: op. cit., p. 178.

${ }^{68}$ En AMAEM, leg. H2491 SGB 1911-1926, carta nº 56, el Capitán Inspector la CAT al Comandante de Marina de Algeciras, Algeciras, 19 de agosto de 1916 anexo Sección Política (en adelante SP) despacho no79, el Cónsul de España en Gibraltar al ministro de Estado, Gibraltar, 25 de agosto de 1916.
} 
Capitán Inspector de la CAT en Algeciras, José de Armiñán, puso en evidencia el respeto que a los patrulleros de Gibraltar mereció la jurisdicción española ${ }^{69}$ : «Repitiome otra vez dicho oficial que los barcos ingleses pueden navegar por donde les dé la gana y con el cargo que quieran y al preguntarle yo, para cortar una conversación que se iba agriando, si podía seguir mi navegación me contestó secamente que no.»

Marina, inhibiéndose como en la cuestión de los hostigamientos a las navieras y siguiendo las recomendaciones del Ministerio de Estado, optó siempre por mantenerse al margen de conflictos de jurisdicción. Se dio prioridad a la cordialidad con los mandos de Gibraltar sobre los intereses del erario español, lo que tampoco supuso novedad alguna ${ }^{70}$. En el caso concreto que acabamos de exponer, José de Armiñán fue desautorizado por la Comandancia de Marina en Algeciras que, a pesar de dirigir una carta de protesta al ministro del ramo por los abusos ingleses, finalmente se atuvo a las instrucciones que vinieron «de arriba». El inspector de la CAT no sólo no contó con el respaldo de sus superiores, sino que además fue blanco habitual de campañas de descrédito de la propaganda británica en Algeciras ${ }^{71}$, reproduciendo la versión de los corresponsales del Times de estos incidentes como atropellos del servicio español ${ }^{72}$.

Pero además de soportar las reiteradas humillaciones de los marinos británicos, el cuerpo local de Marina también se vio disminuido en el desempeño de sus funciones por la intensificación del tráfico portuario en Gibraltar, sobre todo, a partir de 1917 con el establecimiento del sistema de convoyes. Era necesario cada vez más hacer «la vista gorda» con los mercantes aliados que fondeaban en aguas españolas. En la desembocadura del río Palmones anclaban rutinariamente más de medio centenar de embarcaciones que, a plena luz del día, efectuaban labores de carga y descarga ante el sonrojo del oficial de aduanas allí destacado. ${ }^{73}$ Podemos imaginar cuál fue la disyuntiva del funcionario de la pequeña aduana de Puente Mayorga, que no debió de encontrar demasiadas dificultades en hacer más rentable la negligencia que el cumplimiento de sus obligaciones.

Teniendo en cuenta que la distancia entre Punta Carnero y Punta Europa, extremos de la bahía, es inferior a $10 \mathrm{~km}$, la dicotomía entre la satisfacción de las necesidades inglesas y la preservación de las apariencias de la neutralidad puso a los miembros de la administración en una situación de descrédito de la

\footnotetext{
69 Ibid.

70 Comín Comín, Francisco y MARTín Aceña, Pablo: Tabacalera y el Estanco del tabaco en España 1936-1998, Madrid, Fundación Tabacalera, 1999, p. 218.

${ }^{71}$ Puede verse la campaña emprendida entre el 25 de septiembre y el 12 de octubre de 1917 por El Campo de Gibraltar contra José Armiñán y el abogado del Estado en Algeciras, Sancho Rentero, bajo el lema de «Dos funcionarios fracasados».

72 «Seizure of a British Ship. Spanish Company's arbitrary action (from our special correspondent)», en The Times, 7 de diciembre de 1918, p. 7.

73 en AMAEM, leg. H2491 SGB 1911-1926, SP 1ª Sección Hoja 189, El Estado Mayor Central al Ministro de Estado, Madrid, 15 de enero de 1917.
} 
que no fue ajena casi nadie. Cualquier observador avezado podía fácilmente reconocer a los buques ingleses e italianos, que solían tener visibles los cañones en la popa así como al torpedero que se encargaba de las operaciones de vigilancia nocturna ${ }^{74}$. No sorprende que una de las principales tareas del agregado naval alemán en España, Von Krohn, consistiese en organizar una red de informadores en Algeciras ${ }^{75}$.

\subsection{Los suministros ${ }^{76}$}

Gibraltar históricamente había mostrado una gran dependencia de su entorno más inmediato para la propia subsistencia. Durante mucho tiempo la colonia volvió la espalda a su Campo, sirviéndose de Marruecos como granero. De hecho, el ritmo de entrada de productos agrarios del Campo en la colonia podría considerarse un factor indicador del estado de las relaciones hispanobritánicas sobre la "Cuestión de Gibraltar». En este sentido, resulta significativo que el Campo de Gibraltar comenzase a sustituir a Marruecos como surtidor de la plaza después de 1907.

El desconcierto por la situación originada en el verano de 1914 se tradujo en dificultades para el avituallamiento de algunos productos básicos a la colonia, sobre todo, de carbón vegetal. Entonces se recurrió al Gobierno español, los suministros desde España vinieron a complementar los que se recibían desde el Marruecos francés ${ }^{77}$. La actitud que adoptaría España hacia las necesidades de los ingleses en Gibraltar quedó despejada muy pronto por el ministro de Estado $^{78}$ :

\footnotetext{
${ }^{74}$ Íbid. el Comandante de Marina de Algeciras a Ministro de Marina, Algeciras, 6 de febrero de 1917.

75 La misión del entonces Teniente Canaris de buscar y preparar colaboradores en las costas de la Bahía de Algeciras ha sido referida en las distintas biografías sobre el mítico personaje, en ABSHAGEN, Karl Heinz: El almirante Canaris, Buenos Aires, Espasa Calpe, 1962, p.35. Sobre la estancia de Canaris en España durante la Primera Guerra Mundial una obra de referencia la hallamos en HönHe, Heinz Canaris. Patriot im Zwielicht. Munich, 1978, cit. en Alfonso Escuadra Sánchez, op. cit., p. 92.

${ }^{76}$ G. Hills aludió a la existencia de «satisfactorios acuerdos» entre Inglaterra y el gobierno de Eduardo Dato para el abasto de la colonia, que «abiertamente» y hasta 1917 habría recibido suministros de Algeciras». Vid. Hills G.: op. cit., p.485. No obstante, como veremos, en el estado actual de nuestra investigación, este esquema del comercio de subsistencias entre Gibraltar y su Campo es susceptible de ser matizado e incluso corregido.

77 En los años inmediatamente precedentes a la guerra, Gibraltar había comenzado tímidamente a abastecerse de su Campo, brindando la oportunidad el encarecimiento de los productos procedentes de Marruecos. Vid. "Trade and Commerce of the Consular District of Seville 1913», en Diplomatic and Consular Reports. Spain, No 5340, Londres, 1914, p. 592.

78 Bermúdez de Castro y O’Lawlor, Salvador: (II Marqués de Lema), La dimisión del Marqués de Villaurrutia de la Embajada de España en París (1914), Madrid: [s.n.], 1929, p. 6.
} 
«En lo internacional, una serie de actos afirmaban nuestra neutralidad benévola sin alharacas ni jactancias, desde mi telegrama de 14 de agosto a nuestro embajador en Londres, en que asegurábamos que ninguna amistad nos era más valiosa que la de la Gran Bretaña y nuestro propósito de demostrarlo en aquel momento por las facilidades para el aprovisionamiento de Gibraltar».

Así las «facilidades» para el abasto de Gibraltar se concretaron en suministros, aunque extraoficialmente permitidos, ilegales, ya que el ejecutivo español, incluso antes de aclarar la posición internacional del país con la Orden de neutralidad de 7 de agosto, había aprobado leyes restrictivas sobre la exportación del carbón nacional, además de las partidas más importantes de legumbres y cereales $^{79}$. Gibraltar no tenía ninguna amenaza que temer desde su Campo, todo lo contrario. El Gobernador Militar del Campo y el de la plaza, subordinados al ministro de Estado español de turno y al embajador inglés respectivamente, fueron los gestores sobre el terreno de los contenidos de la «relación preferente» con la colonia ${ }^{80}$. El General Arturo Alsina en los primeros meses de la guerra, como Delegado especial de Hacienda, ordenó a los oficiales de la aduana de Algeciras hacer dejación de sus funciones permitiendo la salida de carbón vegetal hacia Gibraltar. Los poderes jurisdiccionales excepcionales de los que disponía el Gobernador Militar del Campo le confirieron un papel protagonista en el régimen de suministros. La reserva en el procedimiento debía ser máxima, pues si estas cesiones se hacían públicas, situarían al Consejo en una tesitura muy complicada. De ahí que para salvar las apariencias, se discurriera un modo alternativo de abastecer a la colonia a salvo de miradas indiscretas: buques despachados para Ceuta, antes de alcanzar su supuesto destino, trasbordarían el cargamento en alta mar a un barco inglés, o bien, escoltados por patrulleros, realizarían la descarga en Gibraltar ${ }^{81}$. El Gobierno español pre-

79 Gaceta de Madrid 04/08/1914 N 216, p. 292. Ministerio de Hacienda. Real Orden disponiendo - hasta nueva orden- la prohibición de la salida al extranjero de los carbones nacionales, oro y plata en monedas, ganados, trigo, maíz, cebada, centeno, arroz, los demás cereales, harinas de todas clases, patatas y alubias blancas y de color. Prohibiciones que, salvo un breve intervalo de dos meses en 1916, y con ciertas variaciones, se mantuvieron durante toda la guerra.

80 En general, a nivel institucional, encontramos en los gestores inmediatos de la excepción hacia Gibraltar una gran estabilidad durante toda la guerra, el Gobernador Militar de la Colonia fue el Teniente General Sir Herbert Scout Gould Miles que se mantuvo en el cargo desde el 30 de julio de 1913 hasta el 11 julio de 1918 cuando fue remplazado por el General Sir Horace Smith-Dorrien, que se había destacado por su actuación en Le Cateau y Mons, Primer y Segundo Ypres; Francisco Martí fue el Cónsul de España durante todo el período hasta su muerte en octubre de 1918, sustituido entonces por el Vicecónsul Antonio Gullón. La figura menos estable fue la del Gobernador Militar del Campo de Gibraltar, sucediéndose en el cargo tres Generales desde el principio hasta el final de la guerra: Arturo Alsina, siendo sustituido por Luis Martí el 15 de noviembre de 1915 y éste a su vez por José Villalba el 28 de mayo de 1917.

81 En AMAEM, leg. 2491 SGB 1911-1916, SP reservado d. s/n, el Ministro de Estado al Director General de Aduanas, San Sebastián, 16 agosto de 1914. 
tendió con estas providencias profundizar en las relaciones de «buena vecindad» entre administraciones amigas y, por qué no, atraer también —en la medida de lo posible - las simpatías de los habitantes del Peñón ${ }^{82}$.

Pero no todas las peticiones cursadas desde Gibraltar fueron atendidas con igual solicitud. El impacto de la contienda en la actividad de los muelles y astilleros del puerto multiplicó las necesidades de aguada ${ }^{83}$. Aunque la colonia tenía garantizado el suministro en botes-aljibes desde Ceuta, por razones obvias interesaba más proveerse desde Algeciras, donde una empresa de capital británico además era la responsable del abastecimiento público de agua. Acceder, en este caso, implicaba desviar parte del tráfico portuario de Algeciras a Gibraltar, por lo que el Ministerio de Fomento desestimó el expediente instruido en octubre de 1914 a petición de Hardinge ${ }^{84}$. En esta cuestión, el Gobierno español modificó su criterio conforme la provisión de agua se hizo imprescindible para la operatividad de la base.

\subsubsection{Gibraltar y su Campo, proveedores a gran escala en el sistema de convoyes.}

El volumen de entrada de subsistencias en Gibraltar creció cuanto más se aplazó la conclusión del conflicto. La aduana de La Línea de la Concepción, desplazando a la de Algeciras, terminó institucionalizándose como la puerta «discreta» de un comercio muy lucrativo. Si sumamos las cantidades extraídas por dicho puesto fronterizo en 1915 y 1916, destacaron como partidas más importantes de este tráfico las siguientes: carbón vegetal (1.102 t.), aceite de oliva $\left(313,7\right.$ t.), patatas $\left(55,5\right.$ t.), harina de trigo $\left(18,1\right.$ t.) y arroz $(9 \text { t. })^{85}$. Estos

82 Íbid., particular, d. s.n., el Gobernador Militar del Campo de Gibraltar a Eugenio Espinosa, Algeciras, 13 de agosto de 1914.

${ }_{83}$ G. Hills estima que fueron reparados en Gibraltar durante la guerra en torno a unos 420 barcos. Si bien se echa en falta una estadística rigurosa al respecto, existen ciertos indicios que hacen pensar en un volumen mayor. Vid. T. M. Benady, The Royal Navy..op.cit., p10; G. Hills, op. cit., pp.481- 485. No cabe duda de que, a pesar de las óptimas condiciones de Malta como puerto y astillero, éstas se vieron depreciadas por su ubicación geográfica, especialmente ante la eventualidad de tener que trasladar buques torpedeados desde el Atlántico o el Mar del Norte derivándose parte de su actividad a Gibraltar.

84 Íbid. particular d. s/n., El Gobernador Militar del Campo de Gibraltar al Ministro de Estado, Algeciras, 17 de octubre de 1914. Vid. En AMAEM, leg. 2491 SGB 1911-1916, privado d. s/n, el Embajador de Gran Bretaña en Madrid al Ministro de Estado de España, Madrid, 22 de octubre de 1914; nota particular, d. s/n, el Ministro de Fomento al Ministro de Estado, Madrid, 12 de diciembre de 1914.

85 Íbid. Nota Dirección General de Aduanas (en adelante DGA) sobre la exportación a Gibraltar por la aduana de La Línea de la Concepción durante 1915, 1916 y los tres primeros trimestres de 1917, adjunto d. s/n., el Ministro de Hacienda al Ministro de Estado, Madrid, 10 de noviembre de 1917. 
artículos pasaban la frontera sin pagar derechos generando enormes perspectivas de negocio para productores y distribuidores como, por ejemplo, Conde Bandrés y Cía, fabricante de harinas con establecimientos en La Línea y Algeciras que también suministraba a las plazas del Norte de África; Pérez y Hermanos de La Línea o Murte y Hermanos de capital inglés, con sedes en Gibraltar y Melilla. Pero fueron muchos más los comerciantes y detallistas favorecidos por la coyuntura ${ }^{86}$. Algunos de ellos tuvieron un órgano de expresión, el diario aliadófilo El Campo de Gibraltar, tildado de «diario torrista» en alusión al periodista José Luis Torres Beleña, en esos años dueño indiscutible del escaño por el distrito $^{87}$. La identificación entre intereses políticos y económicos en el negocio del abastecimiento de Gibraltar resultaba evidente en la comarca. La familia Larios, por el papel predominante que jugaban en el Campo y su presencia a ambos lados de la Verja, difícilmente pudo ser ajena al trasiego operado en la aduana linense ya que La Sociedad Industrial y Agrícola del Guadiaro (SIAG) controlaba la mayoría de los recursos agrarios de la zona ${ }^{88}$.

La puesta en marcha del sistema de convoyes en la primavera de 1917 desbordó todas las expectativas de negocio por la aduana de La Línea de la Concepción. El agotamiento de los bienes energéticos, los problemas para la movilización de tonelaje mercante y la guerra submarina recortaron drásticamente los suministros procedentes del resto del Imperio así como del Marruecos francés, justo cuando Gibraltar más los necesitaba. Un Aviso aparecido en la Gaceta Oficial de la plaza anunció a fines de mayo de ese año la interrupción de la importación de alimentos del Reino Unido por necesidades en el frente ${ }^{89}$. Las demandas de los convoyes que partían desde Gibraltar y el incremento de la población militar en el otoño, como consecuencia de la presencia norteamericana, dispararon las exigencias de alimentos y agua. El cotejo de las estadísticas oficial y oficiosa de la Dirección General de Aduanas refleja el salto cuantitativo que a partir de 1917 se produjo en el comercio registrado por la aduana de La Línea de la Concepción:

${ }^{86}$ Hermanos Hita, Hijos de Ballesteros, José Ruiz Matas, Ricardo Rivas..etc. en íbid, anexo Sección Comercio, despacho núm. 18, el Cónsul de España en Gibraltar al Ministro de Estado, Gibraltar, 10 de febrero de 1918.

87 José Luis Torres Beleña fue diputado por el distrito de Algeciras desde 1910 hasta 1923 , llegándose de forma excepcional, en relación a los otros dos distritos de la provincia de Cádiz, a aplicar sucesivamente el artículo 29 para su elección. Liberal y luego conservador, sin duda personificó intereses representativos y arraigados en la circunscripción

${ }^{88}$ Los terrenos de la Sociedad abarcaban casi 25.000 has en los términos de Jimena, Casares, Manilva, Gaucín, San Roque y Los Barrios. Usufructuarios de la mayor parte de los montes públicos de la zona, los Larios fueron promotores de una incipiente industria de explotación corchera. JiMÉNEZ BLANCO, José Ignacio: «Los Larios y la Industria Corchera. Un caso de industrialización fallida en el Campo de Gibraltar» en Revista de Historia Industrial 27 (25), pp. 49-89.

89 En AMAEM, leg. H1899 CCEG 1913-1932, SP despacho núm. 49, el Cónsul de España en Gibraltar al Ministro de Estado, Gibraltar, 1 de junio de 1917. 


\section{No 1: CÓMPUTO TOTAL DE EXPORTACIÓN A GIBRALTAR POR EL CON- JUNTO DE LAS ADUANAS ESPAÑOLAS (KG)}

\begin{tabular}{|l|r|r|r|r|}
\hline Producto & \multicolumn{1}{|c|}{1914} & \multicolumn{1}{c|}{1.915} & \multicolumn{1}{c|}{1916} & \multicolumn{1}{c|}{1917} \\
\hline Aceite de oliva & 1.022 .687 & 1.565 .189 & 127.759 & 453.166 \\
\hline Arroz & 93.446 & 39.049 & 15.530 & 64.845 \\
\hline Aves de corral & 3.720 & & 1.832 & \\
\hline Carbón vegetal & 306.456 & 883.026 & 529.224 & \\
\hline Carnes frescas & & & 40.392 & 630 \\
\hline Garbanzos & 14.577 & 17.321 & 1.970 & 701.982 \\
\hline Guisantes verdes & & 11.440 & 550 & \\
\hline Harina de trigo & 17.982 & & 18.100 & \\
\hline Patatas & 134.962 & 978.815 & 132.714 & \\
\hline
\end{tabular}

Fuente: Estadística General de Comercio Exterior de España para los años 1914, 1915, 1916 y 191790

\section{No 2: CÓMPUTO DE EXPORTACIÓN A GIBRALTAR POR LA ADUANA DE LA LÍNEA DE LA CONCEPCIÓN (KG) ${ }^{91}$}

\begin{tabular}{|l|r|r|r|}
\cline { 2 - 4 } \multicolumn{1}{c|}{} & \multicolumn{1}{c|}{1.915} & \multicolumn{1}{c|}{1916} & \multicolumn{1}{c|}{1917} \\
\hline Aceite de oliva & 178.611 & 135.095 & 37.661 \\
\hline Arroz & 1.243 & 7.820 & 402.950 \\
\hline Aves de corral & & 1.832 & 12.000 \\
\hline Carbón vegetal & 667.046 & 434.979 & 1.440 .000 \\
\hline Carnes frescas & & 40.392 & 737.004 \\
\hline Garbanzos & 18.216 & & 191.935 \\
\hline Guisantes verdes & 10.480 & 550 & 95.947 \\
\hline Harina de trigo & & 18.100 & 1.177 .045 \\
\hline Patatas & 49.987 & 5.569 & 600.000 \\
\hline
\end{tabular}

Fuente: nota de la DGA remitida por Hacienda al ministro de Estado en febrero de 1918

Aunque las series mostradas no se hallan completas para las distintas partidas ni en la Estadística General de Comercio Exterior ni en el informe reservado de la Dirección General de Aduanas sobre la exportación por La Línea, es evidente

90 Memoria General de Comercio Exterior de España (Países de destino, partidas, provincias y aduanas para los años 1914, 1915, 1916, 1917), en Estadística General del Comercio Exterior de España 1918, Biblioteca del Archivo General del Ministerio de Hacienda, O.P. 235/ 173. He seleccionado aquellas partidas significativas del comercio efectuado por la aduana de La Línea, cuyas series estadísticas se hallaban más completas.

${ }_{91}$ En AMAEM, leg. H2491 SGB, d. s./n. 
el aumento espectacular de las cantidades salidas hacia Gibraltar entre 1916 y 1917, superando ampliamente la exportación por la aduana de La Línea a la efectuada por el conjunto de todas las aduanas españolas. El «Estado de los artículos alimenticios de probibida exportación, salidos por la Aduana de La Línea de la Concepción, con destino al abastecimiento de Gibraltar durante el mes de octubre de 1917» anotó un incremento desorbitado del tráfico ${ }^{92}$ : ganado vacuno (47,4 t); ganado lanar (18 t); ganado porcino (3,6 t); carbón vegetal (135 t); harina de trigo (142,2 t); maíz (4,3 t); garbanzos (33,7 t); harina de garbanzos $(8,1 \mathrm{t}$ ); alubias (68,3 t); arroz (67,5 t); guisantes $(7,6 \mathrm{t})$; habas $(7,5 \mathrm{t})$; lentejas $(28,3 \mathrm{t})$; patatas $(79,2 \mathrm{t})$ y pan $(23,7 \mathrm{t})$. Según estos datos, tomando como base una población máxima de 20.000 habitantes en la Roca, el consumo mensual de pastas y arroces por persona debió ser de $16,25 \mathrm{~kg}$., mientras que el promedio diario de consumo de carne por habitante (sin incluir tocinos y jamones lo que elevaría la estimación) habría estado en casi 300 gramos. La correlación entre la exportación desde el Campo de Gibraltar y la importante función logística asumida por la base en 1917 apareció clara: se estaba abasteciendo por La Línea a las flotas que recalaban en el puerto británico93. Además la entrada de productos del Campo favoreció el papel de la colonia como centro de redistribución en el Mediterráneo, mediante la reexportación ya fuera vía Tánger, Marsella o Malta. Así, Gibraltar se convirtió «through circumstances rather by design as a war profiteer on the grand scale» ${ }^{94}$. El Campo, lejos de suponer una amenaza para la operatividad de Gibraltar, contribuyó a impedir su colapso como enlace en el sistema de convoyes. La autorización del suministro de agua desde Algeciras en el verano de 1917 reforzó el apoyo logístico que se venía prestando a la plaza desde su hinterland ${ }^{95}$.

Pero las consecuencias económicas y sociales de la exportación en el Campo terminaron sobrepasando los cálculos iniciales del Ejecutivo español. El abastecimiento por la aduana linense era un secreto a voces en la comarca. En el invierno de 1917 la Dirección General de Aduanas solicitó al Gobierno que tomase cartas en el asunto para enmendar el «prestigio y la honorabilidad de la Administración» ${ }^{96}$. La primera medida del Ministerio de Hacienda se dirigió a atajar la reexportación mediante el establecimiento de un sistema de vales donde se fijaba el producto y la cantidad a exportar, especificándose además las casas comerciales

\footnotetext{
92 «Estado de los artículos alimenticios de probibida exportación, salidos por la Aduana de La Línea de la Concepción, con destino al abastecimiento de Gibraltar durante el mes de octubre de 1917» en Ibíd.

93 Íbid. d. s/n., el Director General de Aduanas al Marqués de Lema, 19 de octubre de 1917.

94 Íbid, telegrama, el agente diplomático de España en Tánger al Ministro de Estado, Tánger 25 de agosto de 1917.

${ }^{95} \mathrm{La}$ reserva en este tema fue máxima, manteniéndose, en principio, al margen a la propia Junta de Obras del Puerto de Algeciras. Íbid., personal y reservado d. s/n, el Ministro de Estado al Ministro de Fomento, Madrid, 1 de junio de 1917.

${ }^{6}$ Íbid. Nota del Director General de Aduanas al Ministro de Hacienda, adjunta d. s/n, el Ministro de Hacienda al Ministro de Estado, Madrid 13 de diciembre de 1917.
} 
involucradas en la transacción ${ }^{97}$. Los artículos prohibidos saldrían - tal y como venía ocurriendo hasta la fecha- libre de tasas, mientras que, en adelante, los géneros cuya venta al extranjero estuviese permitida tendrían que satisfacer el canon legislativamente estipulado. Sin embargo, la negociación con el Gobierno de la colonia sobre la fórmula de fiscalización encontró dos escollos insalvables: los pormenores de la información que debía incluirse en los vales y, lo más importante, las cantidades a exportar anualmente por cada partida.

\section{No 3: LÍMITES A LA EXPORTACIÓN 1918}

\begin{tabular}{|l|c|c|}
\cline { 2 - 3 } \multicolumn{1}{c|}{} & $\begin{array}{l}\text { Máximo permitido de exporta- } \\
\text { ción anual por la Aduana de La } \\
\text { Línea (toneladas) }\end{array}$ & $\begin{array}{l}\text { Cantidad solicitada } \\
\text { (toneladas) }\end{array}$ \\
\hline Aves & 2 & 12 \\
\hline Carbón vegetal & 435 & 1.444 \\
\hline Cebada & 14 & 540 \\
\hline Embutidos & 6,5 & 18 \\
\hline Fideos & 0,3 & 90 \\
\hline Garbanzos & 21,2 & 180 \\
\hline Grasa de Cerdo & 0,4 & 54 \\
\hline Harina de trigo & 18,1 & 2.700 \\
\hline Harina de garbanzos & 18,1 & 144 \\
\hline Maíz & 3,2 & 180 \\
\hline Pan & 52,6 & 540 \\
\hline Patatas & 5,6 & 720 \\
\hline Salvado & 2,3 & 180 \\
\hline
\end{tabular}

Fuente: Nota de la DGA al Ministro de Hacienda (9 de febrero de 1918)98

La falta de acuerdo con las autoridades inglesas, la resistencia de los distribuidores a cualquier restricción y, por tanto, la intensificación del contrabando hicieron fracasar los intentos españoles de atenuar el problema de la extracción masiva de víveres ${ }^{99}$. Aunque la crisis general de subsistencias durante mucho 1917.

${ }_{97}$ Íbid., reservada y urgente d. s/n, el Ministro de Hacienda al Ministro de Estado, 29 de agosto de

98 «Nota de los artículos alimenticios que podrían exportarse tan sólo en las cantidades anuales expresadas» Madrid, 19 de octubre de 1917, el Director General de Aduanas al Marqués de Lema, d. cit.; Nota de la DGA al Ministro de Hacienda (9 de febrero de 1918), cfr. Íbid., el Ministro de Estado al Embajador de Gran Bretaña en Madrid, Madrid, 14 de febrero de 1918.

99 En Archivo Histórico Nacional, Sección Ministerio de Hacienda, Fondos Contemporáneos, libro $n^{\circ} 3266$ causas por contrabando en la provincia de Cádiz, órdenes $n^{\circ} 17$ y 26, (1917); libro $n^{\circ}$ 
tiempo no se había sufrido con todo su rigor en la comarca, la situación cambió en el verano de 1918. La Junta de Subsistencias de Cádiz se vio obligada a intervenir decretando prohibiciones a la salida de grano en contra de las disposiciones del Gobernador Militar del Campo. Paradójicamente tan sólo la compra de harinas en la colonia permitió aliviar un estado de tensión social que no tardó en estallar ${ }^{100}$.

\subsection{Vigilancia y sabotaje}

Gibraltar se destacó muy pronto como un claro objetivo del sabotaje alemán en la Península Ibérica ${ }^{101}$. El éxito de una acción hostil contra Gibraltar no sólo implicaba asestar un golpe al centro de operaciones para la estrategia aliada en España y el norte de África, también resultaba muy rentable a efectos de propaganda. Al igual que en los apartados precedentes, la cooperación de la administración española se manifestó clave para contrarrestar la amenaza que suponía el espionaje alemán en el Campo de Gibraltar.

Entre 1914 y 1918 La Línea de la Concepción, que prácticamente duplicó su número de habitantes, fue más que nunca «un barrio obrero» de la colonia ${ }^{102}$. La multiplicación de las labores de reparación de buques, carboneo y estiba en Gibraltar atrajeron masivamente mano de obra del interior del Campo y de ciudades costeras próximas como Málaga ${ }^{103}$. De esta forma, la facilidad para confundirse entre la masa de trabajadores desplazados y hacinados en la Línea, ejerció de reclamo para un gran número de agentes alemanes que proliferaron por el arco de la bahía de Algeciras, muchos de ellos reclutados entre la clase obrera. Dos fueron los objetivos fundamentales del espionaje enemigo en la comarca: la vigilancia de los movimientos del tráfico mercante aliado que pasaba por Gibraltar y la realización de acciones de sabotaje, ya fuera en la colonia inglesa o tomando Algeciras como cabeza de puente para actuar en Marruecos ${ }^{104}$. El contraespionaje británico en la provincia de Cádiz contó con la

3267, órdenes $\mathrm{n}^{\circ} 1, \mathrm{n}^{\circ} 9, \mathrm{n}^{\circ} 12, \mathrm{n}^{\circ} 13, \mathrm{n}^{\circ} 14, \mathrm{n}^{\circ} 16, \mathrm{n}^{\circ} 23, \mathrm{n}^{\circ} 25, \mathrm{n}^{\circ} 26, \mathrm{n}^{\circ} 28, \mathrm{n}^{\circ} 37, \mathrm{n}^{\circ} 38, \mathrm{n}^{\circ} 48, \mathrm{n}^{\circ} 50$, $\mathrm{n}^{\mathrm{O}} 51,(1918)$.

${ }^{100}$ El nuevo Gobernador de la Colonia en sustitución del General Miles, el General Mayor Smith Dorrien, inauguró su mandato con un acto de buena vecindad autorizando a la Junta Local de Subsistencias a comprar harinas en Gibraltar, en AMAEM, leg. H2491 SGB 1911-1926, particular (minuta), el Ministro de Estado a Charles John Tudor Vaughan, San Sebastián, 9 de septiembre de 1918.

${ }_{101}$ Respecto al papel de Gibraltar en la organización de las labores de inteligencia en Marruecos, véase la alusión de BRADFORD, ERNLE, op. cit., p. 178.

102 Trinidad PÉreZ, Francisco: Los trabajadores gaditanos en la coyuntura de la Primera Guerra Mundial (1914-1923), Cádiz, Universidad, 2001, p. 159.

103 Ocaña, Mario (coord.), op. cit, p. 296 (II).

104 "Autrian suspect at Gibraltar» (24 noviembre 1914), en The Times, 30 de noviembre de 1914, p. 7; "German arrested at Algeciras. Attempt to enter Gibraltar in disguise.», en The Times, 28 de diciembre de 1914, p. 6. 
asistencia de la policía española, que siguió con atención los movimientos de los agentes alemanes y organizó dispositivos especiales para - llegado el momento- detenerlos. Un número considerable de los expedientes instruidos por la Dirección General de Seguridad pertenecieron a personas identificadas por los servicios de información de países aliados y cuyos nombres fueron facilitados por sus respectivas legaciones diplomáticas ${ }^{105}$. Hardinge, cada vez que coincidía en algún acto social con el ministro de Estado, no desaprovechaba la ocasión para hacerle informalmente alguna indicación en este sentido ${ }^{106}$. El seguimiento a súbditos alemanes residentes en España fue una muestra evidente de proclividad hacia los aliados que no pasó desapercibida para el embajador alemán, quien pidió explicaciones en más de una ocasión al Gobierno español ${ }^{107}$.

Una de las fórmulas de sabotaje más efectivas contra Gibraltar fue «la huelga», pues la labor diaria de 8.000 a 9.000 operarios españoles se convirtió en indispensable para evitar el colapso de los muelles ${ }^{108}$. Los obreros que trabajaron en la colonia, al igual que los de otros centros industriales estratégicos cuya dirección estuvo al servicio de los aliados en Andalucía (The Tinto Company Limited en Huelva, en The Seville Sulphur and Copper Co. Ltd. o en la Sociedad Minero Metalúrgica de Málaga), fueron destinatarios prioritarios de la propaganda subversiva alemana. Las autoridades inglesas, reacias a sustituir a los operarios del Campo por mano de obra procedente de Marruecos, ante el temor a que se infiltrase algún espía de los empresarios alemanes Mannesmann, temieron especialmente los paros en la actividad ${ }^{109}$. En este sentido resultó frecuente que los carboneros y estibadores hicieran valer su posición de monopolio respecto a la oferta de trabajo para conseguir mejoras salariales ${ }^{110}$. No obstante, salvo los paros que se desarrollaron en enero y junio de 1917, la incidencia de la actividad huelguísti-

105 En AMAEM, leg. H2491 SGB 1911-1926, confidencial (recibido por telégrafo el 6 de marzo de 1915), el Gobernador Militar del Campo de Gibraltar al Ministro de Estado, Algeciras, 3 de marzo de 1915

106 Íbid, Amalio Gimeno a Joaquín Ruiz Jiménez, particular, Madrid, 25 de enero de 1917.

107 El Príncipe de Ratibor pide explicaciones a Amalio Gimeno por la solicitud de Gobernación a los Consulados alemanes de información acerca de súbditos alemanes residentes en España. En íbid, leg. H1346 CELA 1911-1916, nota n³789, el Embajador de Alemania en Madrid al Ministro de Estado, Madrid, 7 de mayo de 1916.

108 En AMAEM, leg. H2491 SGB 1911-1926, particular y confidencial d. s/n, el Embajador de Inglaterra al Ministro de Estado, Madrid, 15 de marzo de 1918.

${ }_{109} \mathrm{La}$ influencia de los empresarios alemanes en el norte de África solía ser la justificación más esgrimida. Los Hermanos Mannesmann fueron técnicos industriales alemanes interesados en las minas del Norte de África donde crearon un emporio comercial, así mismo tuvieron presencia económica en ciudades andaluzas como Málaga. Íbid, SP despacho núm. 15, el Cónsul de España en Gibraltar al Ministro de Estado, Gibraltar, 30 de enero de 1917.

110 La pérdida de poder adquisitivo de los trabajadores gaditanos entre 1914 y 1920 estuvo cuatro puntos por debajo de la media del resto de las provincias españolas, cifrándose en un 17\% frente al $21 \%$ nacional, y los trabajadores en Gibraltar fueron en este sentido de los más privilegiados TRINIDAd PÉReZ, Francisco: op. cit., p. 158/ 288. 
ca en Gibraltar fue moderada hasta el verano de 1918. Los efectos de la crisis de subsistencias en la comarca y la extensión de los conflictos laborales en Andalucía entre 1918 y 1921, dentro del contexto de huelgas y violencia conocido como Trienio Bolchevique, terminaron solapándose en el impulso del asociacionismo obrero del Campo de Gibraltar, del mismo modo que en las motivaciones de la policía a la hora de ejercer el control y represión sobre el mismo ${ }^{111}$.

\section{EPÍLOGO: La política española hacia Gibraltar}

La política sobre Gibraltar establecida por el gabinete de Eduardo Dato en el mes de agosto de 1914, a pesar de la inestabilidad ministerial, se mantuvo a lo largo de toda la coyuntura internacional ${ }^{112}$. ¿Subyacía en esta actitud benevolente de los ejecutivos españoles alguna esperanza sobre la restitución?

Según la mayoría de autores, España durante la guerra nunca reclamaría Gibraltar oficialmente, algo que en marzo de 1917 habría confirmado la destitución de Primo de Rivera, hasta entonces Gobernador Militar de Cádiz, para evitar que sus declaraciones sobre la restitución enturbiasen el clima bilateral de inteligencia ${ }^{113}$. Precisamente en ese mismo año se creó una comisión interministerial en Londres para elaborar un informe sobre la conveniencia de la permuta de Gibraltar por Ceuta. Una revisión favorable para los intereses españoles del estatuto de Tánger y margen de maniobra para intervenir en Portugal habrían sido las dos exigencias manifestadas por Alfonso XIII a cambio de un mayor compromiso con la Entente. Pero las veleidades del monarca difícilmente podrían haber alcanzado algún viso de realidad, ni tan siquiera en un hipotético escenario internacional — que nunca se produjo- en el que el país hubiera abandonado la neutralidad. Este régimen de excepción hacia Gibraltar tuvo contraprestaciones, aunque en proporcionalidad a los gestos en los que se

111 «Spanish strikers at Gibraltar. German intrigue (from our special correspondent)», en The Times, 6 de septiembre de 1918, p.5. Las noticias de intentos desesperados de sabotaje alemán desde Algeciras fueron noticia de nuevo, "German agents caught red-handed. Another Morrocan intrigue (from our correspondant)», en The Times, 28 de septiembre de 1918, p. 5.

112 Gobiernos presididos por Eduardo Dato, 27 de octubre de 1913-9 de diciembre de 1915; 11 junio-3 de noviembre de 1917. Gobierno presidido por el Conde de Romanones, 9 de diciembre de 1915- 19 de abril de 1915; Gobiernos de Manuel García Prieto, 19 de abril -11 junio de 1917; 3 de noviembre de 1917- 22 de marzo de 1918; Gobierno de Antonio Maura, 22 de marzo-9 de noviembre de 1918.

$113 \mathrm{Al}$ parecer Alfonso XIII mantuvo una postura un tanto ambigua en torno a Gibraltar durante la guerra. Pues, si bien no realizó a Gran Bretaña ninguna reclamación sobre el Peñón, desde Palacio se solicitó en la primavera de 1915 un informe sobre las reivindicaciones sostenidas por España sobre la colonia desde el inicio del contencioso, en TUSELl, Javier y QUEIPO DE LLANO, Genoveva: Alfonso XIII: el rey polémico, Madrid, Santillana, 2001, p. 290. Véase también el tratamiento difuso de la cuestión en ROMERo SALVADÓ, Francisco J.: España 1914-1918. Entre la guerra y la revolución, Barcelona, Crítica, 2002. 
consignó la orientación oficiosa de la política exterior española. El agradecimiento expresado por el Secretario de Estado del Foreign Office en septiembre de 1914 se tradujo en hechos tangibles ${ }^{114}$. Las facilidades para el abastecimiento de carbón mineral tanto a la marina mercante como a la armada española en Ceuta y Málaga, además del transporte de frutas y críticos del Mediterráneo a puertos del norte de Europa fueron hasta 1918 dos buenos ejemplos de reciprocidad, especialmente el segundo de los $\operatorname{casos}^{115}$. Teniendo en cuenta las restricciones a las importaciones publicadas en la Gaceta de Londres y los problemas para reunir tonelaje, el hecho de que los cónsules ingleses de los puertos del Levante autorizasen el despacho de estos productos no resultaba en absoluto irrelevante. El Times incluso llegó a hacer campaña por la cooperación bilateral en esta materia ${ }^{116}$.

No obstante, el estado general de entendimiento hispano-británico durante la guerra, basado en un principio de equivalente compensación, no debe hacernos pensar que las relaciones entre los dos países fueron siempre una balsa de aceite, pues en más de una ocasión afloraron tensiones producto de una desconfianza mutua. Y España tenía más que perder. El Gobierno español tuvo miedo de que el servicio secreto británico — sin su conocimiento- pusiese en un aprieto la neutralidad oficial, dirigiendo actividades desde Gibraltar en su territorio. El estrecho seguimiento policial sobre el Gobernador de la plaza en una visita que realizó en el otoño de 1915 a las provincias de Andalucía occidental constituyó una prueba evidente de lo anterior. Los informes españoles concluyeron que el propósito del General Miles no era otro que convencer a la colonia inglesa para que —en un alarde de patriotismo- acogiese a soldados convalecientes y así paliar el problema sanitario que éstos estaban provocando en Gibraltar tras su llegada masiva desde los Dardanelos. El Gobernador también aprovechó la ocasión para pulsar la opinión de sus compatriotas sobre los suministros a submarinos en Huelva ${ }^{117}$. Por su parte, los ingleses, a pesar de la cooperación prácticamente sin titubeos que se les había prestado desde el principio de la guerra, tampoco se sintieron siempre seguros de las intenciones españolas. La ambigüedad entre la posición oficial y oficiosa del Gobierno español dejó algún resquicio de duda. En marzo de 1916 una anécdota en la

114 No39 Commercial (44857/14) 3 de septiembre de 1914 (Copia del original enviado a título de devolución por el Embajador británico al Ministro de Estado en carta particular el 20 de septiembre de 1914), en AMAEM, leg. 2491 SGB 1911-1926.

115 vid. Íbid., comunicación de la Secretaría Colonial anexo al despacho consular, SC núm.19, Gibraltar, 11 de febrero de 1918; en AMAEM, leg. H2491 SGB 1911-1926, (minuta verbal n ${ }^{\circ}$ 8079), el Ministro de Estado al Embajador de Gran Bretaña en Madrid, Madrid, 14 de febrero de 1918.

116 «English and Spanish interests», en The Times, 26 de febrero de 1916, p.7. El contrapunto - a efectos de propaganda- lo hallamos en «España y los aliados. Lo que nos deben y nos niegan», en $A B C, 5$ de marzo de 1916, p. 12.

117 «German submarines in the Gibraltar Straits. Four steamers sunk», en The Times, 8 de noviembre de 1915, p.8; «German submarines «Supplies for German Submarines. Smuggling from Spain (from a Correspondent in Spain)», en The Times, 26 de noviembre de 1915, p. 7. 
aduana de La Línea vinculó los acuerdos sobre el avituallamiento de Gibraltar con un cambio producido en la situación internacional. El nuevo administrador de la aduana que desconocía el compromiso tácito del Gobierno español para el suministro de la colonia inglesa, impidió la salida de los productos de prohibida exportación que diariamente entraban en la colonia. La respuesta inglesa no se hizo esperar: Hardinge, bajo la sospecha de que la interrupción de los suministros obedeciese realmente a una represalia del Gobierno español por la entrada de Portugal en la guerra, amenazó con una cuestión tan importante como la suspensión de las importaciones de cítricos desde Gran Bretaña ${ }^{118}$. Pero a pesar de lo desencuentros que pudieron surgir en momentos puntuales, lo cierto es que no fue hasta el invierno de 1918 cuando se produjeron las mayores dificultades en la inteligencia hispano-británica en torno a Gibraltar.

La falta de entendimiento en cuestiones de alto nivel bilateral como los problemas para la ratificación del convenio comercial hispano-británico, conocido como "Acuerdo Cortina», y la negociación del posterior convenio financiero, comprometieron la exportación por la aduana de La Línea de la Concepción $^{119}$. Los enfrentamientos más duros se dirimieron entre Manuel García Prieto y Arthur Hardinge en los meses de febrero y marzo de 1918. Las restricciones inglesas al pertrecho de carbón mineral de los mercantes españoles en Gibraltar y la negativa a refrendar el modelo de vale de la Dirección General de Aduanas no fueron precisamente bien acogidos por el Marqués de Alhucemas, quien no accedió a la ampliación de las licencias de exportación a la colonia $^{120}$. Pero la situación de tirantez entre administraciones no fue una cuestión de mayor o menor voluntad política, sino producto de las graves consecuencias del duro invierno de 1918 para ambas partes. La merma alarmante en recursos energéticos de Inglaterra y la aguda crisis de subsistencias en los mercados internos españoles, junto a la huelga general revolucionaria de agosto de

118 En AMAEM, leg. H2491 SGB 1911-1926, particular d. s/n, el Embajador de Gran Bretaña en Madrid al Presidente del Consejo de Ministros, Madrid, 13 de marzo de 1916. El día 10 de marzo Alemania declaraba la guerra al gobierno luso. Sobre Portugal como factor de desestabilización del neutralismo español, vid. De LA TORRE, Hipólito, El imperio del Rey: Portugal y los ingleses (19071916), Mérida, Junta de Extremadura, 2002, pp. 143-161.

${ }_{119}$ En marzo de 1917 el senador vitalicio, José Gómez Acebo y Cortina, Marqués de Cortina, fue designado para llevar una negociación comercial con el Gobierno británico, cuyo resultado conocido como «Convenio Cortina» si bien se concretó en abril, no pudo ratificarse, tras la caída del gobierno Romanones que lo había designado, hasta diciembre de ese mismo año por las continuas crisis ministeriales que se sucedieron. En cuanto a la conexión del régimen de favor hacia Gibraltar con acuerdos comerciales de índole bilateral, vid. AMAEM, leg. H1899 CCEG 1913-1932, SP despacho núm. 49, el Cónsul de España en Gibraltar al Ministro de Estado Gibraltar, 1 de junio de 1917.

120 «no dejará Ud. de hacerse cargo de que las circunstancias angustiosas que España atraviesa no consentirían una mayor largueza en este importantísimo servicio, que de otra parte, además de las difíciles circunstancias aludidas, se está dando sin compensación alguna, para el aprovisionamiento de la plaza de Gibraltar», íbid leg. H2491 SGB 1911-1926, (minuta), el Marqués de Albucemas a Arthur Hardinge, Madrid, 14 de febrero de 1918. 
1917, establecieron un escenario de partida en el que aunar posiciones sobre las cantidades a exportar no resultó fácil. Además los obreros del Campo de Gibraltar comenzaron a boicotear el paso de mercancías por la aduana de La Línea ante la negativa de las autoridades de la colonia a aceptar sus reivindicaciones salariales ${ }^{121}$. En estas condiciones Londres dio por hecho más cesiones de las que el Marqués de Alhucemas pudo aceptar. Su sustitución al frente del Consejo por Antonio Maura contribuyó a recobrar la cordialidad en las comunicaciones con el embajador inglés. A pesar de todo, la inteligencia extraoficial contraída desde el principio de la guerra nunca llegó a ponerse en entredicho. El mismo García Prieto autorizó el suministro de agua a Gibraltar desde Algeciras, desestimando además la solicitud de la Junta de Obras del Puerto sobre el cobro de un canon por cada tonelada transferida a la colonia ${ }^{122}$.

El desequilibrio manifiesto entre ambas partes demostró, al margen del signo de los gabinetes que se sucedieron entre 1914 y 1918, qué intereses — por las buenas o por las malas- prevalecieron. España cooperó en todas las cuestiones que Gran Bretaña le planteó en torno a Gibraltar, impidiendo el estrangulamiento operativo de la base naval a partir de 1917. Sólo quedaría preguntarnos si la proclividad española en el Campo de Gibraltar fue respetuosa con los Protocolos de La Haya (1899 y 1907). Pero como ha escrito Manuel Espadas Burgos, la neutralidad es una cuestión de «perfiles cambiantes y delicada matización» ${ }^{123}$ y aunque la política hacia Gibraltar de los distintos gabinetes españoles distó de situarse bajo el principio de la ecuanimidad en relación a los dos bandos beligerantes, queda mucho por investigar y discernir antes de entrar en discusiones legalistas, la mayoría de las veces estériles.

121 Íbid, telegrama cifrado $\mathrm{n}^{\circ} 2115$ expedido a las 23 h.; recibido en Madrid 25 de junio a las 11 h., el Gobernador Militar del Campo de Gibraltar al Ministro de Estado, Algeciras, 24 de junio de 1917.

122 Íbid, reservado d. núm. 119, el Ingeniero Director del Puerto de Algeciras al Gobernador Militar del Campo de Gibraltar, Algeciras, 14 de noviembre de 1917.

123 Espadas Burgos, M.: «España y la Guerra», en Gil PeCharromÁn, Julio: La Gran Guerra. Años de sangre, ruinas y miseria, Madrid, Historia 16, 1997, p.87. 